\title{
Clinical Effectiveness of Liraglutide in Type 2 Diabetes Treatment in the Real-World Setting: A Systematic Literature Review
}

\author{
Amrita Ostawal · Emina Mocevic · Nana Kragh $\cdot$ Weiwei Xu
}

Received: May 10, 2016 / Published online: June 27, 2016

(C) The Author(s) 2016. This article is published with open access at Springerlink.com

\begin{abstract}
Introduction: In clinical trials, liraglutide has proven to be an effective drug for the treatment of type 2 diabetes mellitus (T2DM). The real-world effectiveness of liraglutide has been investigated in numerous studies. The aim of this systematic literature review is to collate evidence on the real-world clinical effectiveness of liraglutide.
\end{abstract}

Methods: A review of publications from Medline, EMBASE, the Cochrane Library, and conference proceedings was conducted to identify observational studies that assessed the

Enhanced content To view enhanced content for this article go to http://www.medengine.com/Redeem/ DBD4F060387252C8.

Electronic supplementary material The online version of this article (doi:10.1007/s13300-016-0180-0) contains supplementary material, which is available to authorized users.

A. Ostawal

Pharmerit GmbH, Berlin, Germany

E. Mocevic $\cdot$ N. Kragh

Novo Nordisk A/S, Søborg, Denmark

W. Xu $(\bowtie)$

Pharmerit International, Rotterdam,

The Netherlands

e-mail: wxu@pharmerit.com clinical effectiveness of liraglutide in real-world clinical practice. This review was conducted according to the National Institute of Health and Care Excellence (NICE) guidance. No language or time limits were applied, except to the conference proceedings (2013-2015). Endpoints for data extraction were decided a priori. Study quality appraisal was done for full-text journal articles.

Results: Of 124 publications included in the review, 43 were full-text articles. Liraglutide significantly reduces glycated hemoglobin (HbA1c) within 6 months of initiating treatment (mean change in HbA1c from baseline: $-0.9 \%$ to $-2.2 \%$; HbA1c $<7.0 \%$ : 29.5-65.0\%). The NICE composite endpoint (HbA1c reduction $\geq 1 \%$ and weight reduction $\geq 3 \%$ ) was met in $16.9-47.0 \%$ of patients with liraglutide treatment. Liraglutide therapy led to a mean change in absolute weight from baseline of -1.3 to $-8.65 \mathrm{~kg}$. Liraglutide treatment was well tolerated in patients with T2DM. The rate of occurrence of hypoglycemia with liraglutide monotherapy was $\leq 0.8 \%$. Hypoglycemia was more common in patients taking antidiabetic medications (0.0-15.2\%) together with liraglutide. The 
beneficial glycemic and weight effect of liraglutide therapy in patients with T2DM was maintained for at least 12 months.

Conclusion: Evidence from observational studies reflecting real-world clinical practice demonstrates that liraglutide therapy improves glycemic control with a low risk of hypoglycemia, and is associated with significant weight loss in patients with T2DM. These observations are consistent with clinical trial findings.

Funding: Novo Nordisk A/S, Søborg, Denmark.

Keywords: Effectiveness;

HbA1c;

Hypoglycemia; Liraglutide; Literature review; Real-world evidence; Safety; Type 2 diabetes; Weight

\section{INTRODUCTION}

Type 2 diabetes mellitus (T2DM) is a chronic metabolic disorder characterized by increased blood glucose levels, i.e., hyperglycemia, which over time can cause microvascular and macrovascular complications [1]. The main goal of T2DM treatment is to achieve and maintain patients' individual target blood glucose levels, thus reducing the occurrence of complications [2].

There are several guidelines for the management of T2DM including those developed by the International Diabetes Federation (IDF) [3], the American Diabetes Association (ADA) [4], the American Association of Clinical Endocrinologists (AACE)/American College of Endocrinology (ACE) [5], and the National Institute of Health and Care Excellence (NICE) from the UK [6]. The treatment recommendations are generally consistent but with some differences. For example, the ADA and the European
Association for the Study of Diabetes (EASD) suggest a treatment algorithm for patients with T2DM [7] which suggests that patients with T2DM should initially be offered education in lifestyle changes, with advice to lose weight by changing dietary habits and increasing physical activity. If a patient's blood glucose level is not decreased to, and maintained at, the individualized target glycated hemoglobin (HbA1c) levels [7], it is recommended that medical treatment with anti-diabetic drugs be initiated. Over the years, glucagon-like peptide (GLP-1) receptor agonists (RAs) have become integral as second- or third-line therapies in many treatment guidelines, such as the ADA/ EASD, the AACE, and the IDF [3-7].

GLP-1 RAs are one among many treatment options available for patients with T2DM. GLP-1 RAs mimic the effects of endogenous GLP-1, which regulates plasma glucose levels by stimulating the secretion and biosynthesis of insulin and by inhibiting the secretion of glucagon and by delaying the gastric emptying of food and reducing food intake $[8,9]$. Based on this mechanism of action, GLP-1 RA has effects on controlling glucose level and reducing body weight. Liraglutide was the second GLP-1 RA that was approved for the treatment of T2DM by the European Medicines Agency (EMA) and the US Food and Drug Administration (FDA) in 2009 and 2010, respectively. Currently, liraglutide is the most used GLP-1 RA worldwide [10]. The efficacy and safety of liraglutide mono- and combination therapy have been evaluated in the Liraglutide Effect and Action in Diabetes (LEAD) clinical program which consisted of six clinical trials [11-16], and recently a clinical trial comparing liraglutide head-to-head with lixisenatide was finalized [17]. There exist a number of different clinical trials on the efficacy of liraglutide, among others comparative trials vs. albiglutide 
[18], dulaglutide [19], exenatide [20], sitagliptin [21, 22], switching to GLP-1 RA from sitagliptin [23] and with other oral antidiabetic drugs (OADs; dipeptidyl peptidase-4 inhibitors [DPP-4i], sulfonylurea [SU], glinide, metformin [MET], $\alpha$-glucosidase inhibitor, or thiazolidinedione [TZD]) [24]. Furthermore, one Japanese trial assessed liraglutide in combination with insulin [25]. Results from all these trials consistently showed that patients treated with liraglutide had significantly improved glycemic control (with a high proportion of patients reaching HBA1c $<7.0 \%$ at the end of the trial) and achieved substantial reductions in absolute body weight. Importantly, these beneficial effects of liraglutide occurred with a low risk of hypoglycemia, and the drug was well tolerated in patients with T2DM [11-25].

Established as a drug with robust clinical efficacy and safety profile in controlled settings, the clinical effectiveness and safety of liraglutide for the treatment of patients with T2DM have also been investigated in observational studies reflecting real-life clinical practice. We performed a systematic literature review to evaluate the effectiveness of liraglutide for the treatment of patients with T2DM in real-world clinical practice. The goal of the review is to provide a succinct overview of the evidence on the clinical effectiveness of liraglutide which could help guide clinical decision making and assist clinicians in deciding how different therapies fit into the current treatment algorithm, and help inform current and future treatment guidelines for the management of patients with T2DM.

\section{METHODS}

This systematic literature review was conducted in accordance with the NICE guidance to obtain relevant information using a consistent, reproducible, and transparent methodology [26]. According to this guidance, this process involves the development of a study protocol (see supplementary file 1), parallel review of retrieved publications by two independent researchers for the selection of relevant publications, followed by a full-evidence data extraction and quality assessment of study methodology, results, and implication of results to routine T2DM clinical practice.

\section{Search Strategy}

To collect evidence on the effectiveness of liraglutide, different databases were selected. These included Medline (1979-2016) and EMBASE (1974-2016; searched simultaneously via ProQuest), Cochrane (1992-2016; Cochrane Database of Systematic Reviews [CDSR]; Database of Abstracts of Reviews of Effects [DARE]; Cochrane Methodology Register [CMR]; Health Technology Assessments Database [HTA]; and The National Health Services [NHS] Economic Evaluation Database [EED]), health technology assessment websites, and conference proceedings (International Society for Pharmacoeconomics and Outcomes Research [ISPOR], ADA, EASD, World Diabetes Congress-IDF [WDC-IDF]).

The search terms included both free-text and Emtree/MeSH terms of indication, clinical effectiveness, comparative effectiveness, generic and brand name of liraglutide, and were designed to meet the requirements outlined in NICE guidelines for the methods of technology appraisal [26]. Complex search strings, combining extensive lists of search terms for indication and topic, were used to search the databases through ProQuest. For other databases, less complex search strings 
were used as the search engines provided fewer options. In all databases, no language or time limits were applied to ensure that no relevant publications were missed. The annual meeting abstracts were only searched for the last 3 years (up until 2015), because it was assumed that after 3 years these would have been published as full publications in a peer-reviewed journal. The search terms that were applied per database are provided in the study protocol (see supplementary file 1 ).

The database searches were executed on October 13, 2015 and an updated search in ProQuest was conducted on January 7, 2016.

\section{Eligibility Criteria}

After all the searches were performed, the results were screened (based on title and abstract followed by full-text review) in parallel by two independent researchers after the removal of duplicate publications. If the researchers could not reach agreement on the selection of a relevant publication, a third independent researcher was consulted to decide eligibility of the publication for the review. The inclusion and exclusion criteria for the screening and selection process are provided in Table 1.

\section{Data Extraction and Assessment of Study Quality}

The data extraction of selected studies was performed by one researcher (AO). A second researcher performed a thorough quality check to assure all relevant data were extracted to the correct parameter (WX). Endpoints for data extraction were decided a priori. These primarily included effectiveness (glucose control and weight) and if the studies identified in the literature search reported safety endpoints (hypoglycemia, adverse events [AEs], serious AEs) related to liraglutide treatment for patients with T2DM, then these were also included. No statistical analyses were performed.

Following data extraction, a critical appraisal of the quality of selected studies was performed by a single researcher (AO), and reviewed by a second researcher (WX). This quality assessment was completed for all selected observational studies that were published in full text based on the recommendations of the Centre for Reviews and Dissemination (CRD) guidance for undertaking reviews in healthcare [27]. The quality of full-text publications was subjectively evaluated based on several criteria including completeness of reporting, study population and design, sample size, sampling procedure, study follow-up duration, treatment setting, patient inclusion and exclusion criteria and patient enrollment and study completion rates. In addition to this, quality appraisal was further informed by assessing potential sources of confounding and biases (e.g., patient baseline characteristics, misclassification, selection bias, reporting bias, etc.) which are known to be prominent in observation studies. The limitations described in the individual articles from the authors' perspective were also used to guide the quality appraisal. The quality assessment of abstracts was not performed as study details were not adequately reported.

\section{Data Reporting}

The results section focuses mainly on the findings from full-text journal publications identified in the systematic literature review. These findings are supplemented with supportive evidence from the conference abstracts. This approach for presentation was chosen because full-text publications are peer 
Table 1 Study eligibility criteria

\begin{tabular}{|c|c|c|}
\hline Item & Inclusion criteria & Exclusion criteria \\
\hline \multirow[t]{3}{*}{ Population } & Patients with T2DM & Type 1 diabetes mellitus \\
\hline & & Gestational diabetes \\
\hline & & Other diseases \\
\hline \multirow[t]{2}{*}{ Intervention } & Treatment regimens including liraglutide & Insulin therapy \\
\hline & & NIADs \\
\hline \multirow[t]{8}{*}{ Comparator } & Treatment regimens including NIADs & Insulin therapy \\
\hline & TZD (e.g., pioglitazone) & \\
\hline & DPP-4i (e.g., sitagliptin or saxagliptin) & \\
\hline & $\begin{array}{l}\text { SGLT2 inhibitor (e.g., dapagliflozin or } \\
\text { canagliflozin) }\end{array}$ & \\
\hline & $\begin{array}{l}\text { GLP-1 RA (e.g., exenatide, albiglutide, or } \\
\text { dulaglutide) }\end{array}$ & \\
\hline & MET & \\
\hline & SU & \\
\hline & Other OADs & \\
\hline Outcomes & $\begin{array}{l}\text { Clinical effectiveness and safety of liraglutide } \\
\text { Comparative effectiveness and safety of } \\
\text { liraglutide compared to other NIADs }\end{array}$ & $\begin{array}{l}\text { Studies not reporting the clinical effectiveness/safety of } \\
\text { either liraglutide compared to other NIADs }\end{array}$ \\
\hline \multirow[t]{6}{*}{ Study design } & Chart review & RCT \\
\hline & Medical record analysis & Case-reports \\
\hline & Database analysis & Letters to editor \\
\hline & Expert panel studies & \\
\hline & Prospective follow-up studies & \\
\hline & Post-marketing surveillance studies & \\
\hline Location & All & None \\
\hline Language & All & None \\
\hline
\end{tabular}

$D P P-4 i$ dipeptidyl peptidase-4 inhibitor, GLP glucagon-like peptide, $M E T$ metformin, NIAD non-insulin antidiabetic drug, $O A D$ oral antidiabetic drug, $R A$ receptor agonist, $R C T$ randomized controlled trials, $S G L T 2$ sodium-glucose cotransporter type-2, $S U$ sulfonylurea, $T 2 D M$ type 2 diabetes mellitus, $T Z D$ thiazolidinedione

reviewed and considered to be of higher quality than abstracts from annual conference proceedings as complete methodological details and results are reported in full-text articles.

\section{Compliance with Ethics Guidelines}

This article is based on previously conducted studies and does not involve any new studies of 
human or animal subjects performed by any of the authors.

\section{RESULTS}

\section{Included Studies}

The database searches resulted in 220 publications from Medline and EMBASE (via ProQuest). No publications were identified in the Cochrane library. A total of 303 publications were found from conference proceedings. After removing 88 duplicates from a total of 523 publications, the title and abstracts of 435 publications were screened for eligibility to a full-text screening. Of 435 publications, 284 were excluded based on title and abstract screening. Of 151 publications, 81 were abstracts from conference proceedings and, therefore, only 70 full-text publications were reviewed for eligibility by full-text screening based on the pre-defined study eligibility criteria. Of these 70 full-text publications, 27 were excluded: 5, 17, and 5 records due to population, outcome, and study design irrelevance, respectively. Thus, 43 full-text publications were included.

One-hundred and twenty-four publications were eventually included in this literature review. Of these, 43 were full-text journal articles, and 81 were abstracts identified from databases of conference proceedings or from published supplements of conference proceedings. The search and selection procedure is shown in the PRISMA flowchart (Fig. 1).

\section{Study Characteristics}

More than half of the 43 full-text journal articles [28-70] had a study design which involved analyses of data that were previously collected from patient medical record/ chart review from hospitals, or databases $(53.5 \% ; N=23) \quad[28,30-33,37,39,40,43$, $44,46,49-51,54-58,61,62,65,70]$. The majority of the studies assessed the clinical effectiveness of liraglutide without an active comparator $(81.4 \% ; N=35) \quad[28, \quad 29,31$, 34, 36-39, 41-49, 51-55, 57, 60-64, 66-71]. Real-world studies with comparators were less frequently observed $(18.6 \% ; N=8)$; the most common comparators for liraglutide were: sitagliptin or any DPP-4i $(N=6)$ $[32,33,35,40,56,58]$, exenatide $(N=3)$ $[33,35,50]$, glimepiride or any other SUs $(N=2)$ [30, 35], pioglitazone or other TZDs $(N=1)$ [35], and $\operatorname{MET}(N=1)$ [35]; note: these numbers do not add up because some studies had more than one comparator. The most frequently observed follow-up duration from these publications was $\geq 12$ months (46.5\%; $N=20)$ [28-47], followed by $6-12$ months (34.9\%; $\quad N=15) \quad$ [48-62], and $<6$ months (18.6\%; $N=8$ ) [63-70]. Real-world studies frequently reported data on the effect of liraglutide from outpatient settings (30.2\%; $N=13) \quad[34, \quad 39, \quad 40, \quad 42-44, \quad 49$, $55,58,60,61,66,67]$. The geographical scope of the review included studies from Europe $(N=24)$, the USA $(N=5)$, and Asia-Pacific $(N=14$; see supplementary file 2$)$.

Study characteristics from the abstracts ( $N=81$; see supplementary file 3 for the full list of conference abstracts included in this review) were similar to those reported from full-text publications. The majority of conference abstracts reported findings from studies involving analyses of already available data $(60.5 \% ; N=49)$, followed by those based on prospective study designs $(24.7 \% ; N=20)$. For the remaining abstracts $(14.8 \% ; N=12)$, information on study design was not reported. 


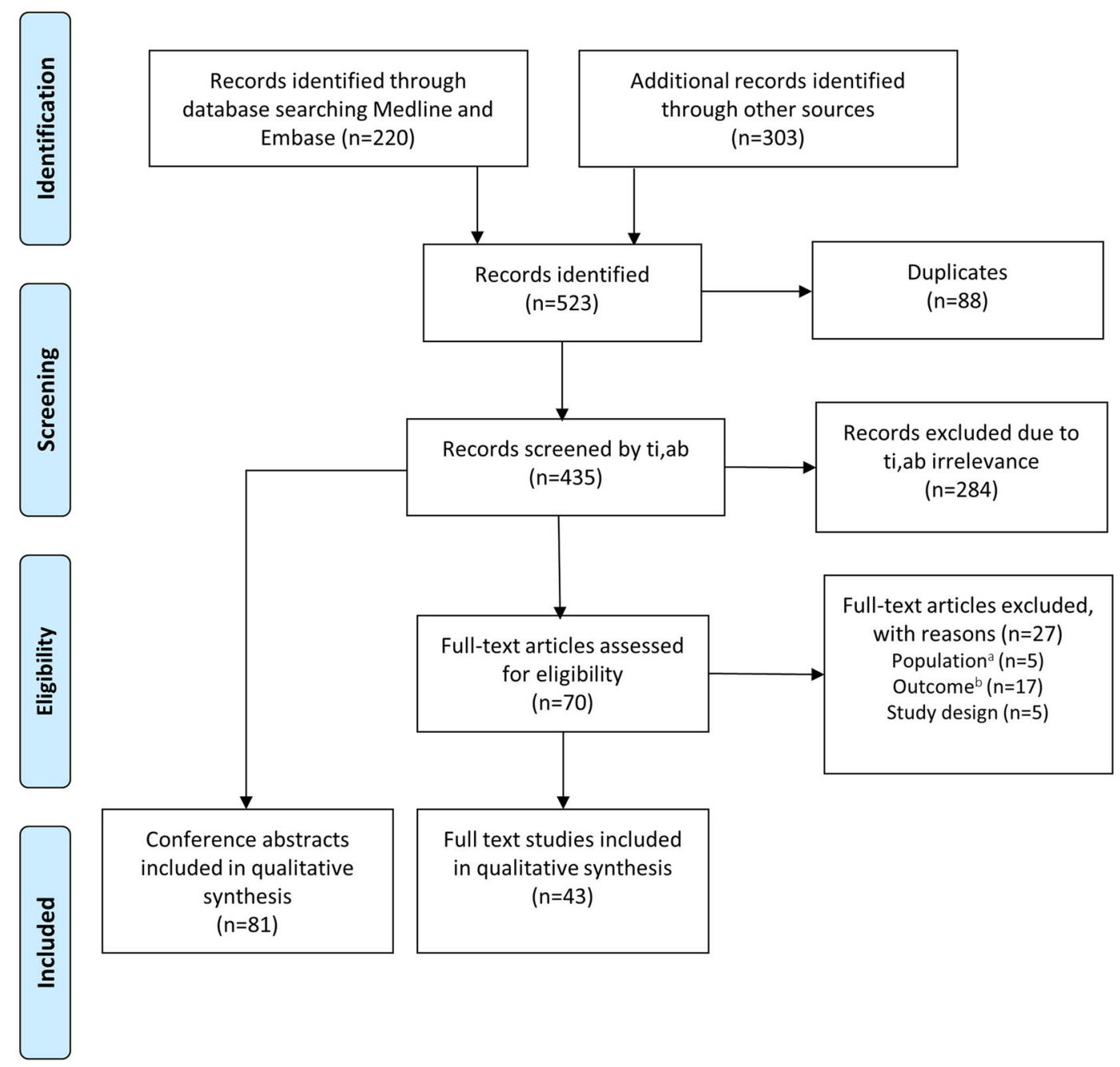

Fig. 1 PRISMA flow diagram. No studies were excluded due to intervention/comparator at the full-text screening stage. Other sources include publications from different conference proceedings (see supplementary file 1). ${ }^{\mathrm{a}} \mathrm{Pa}$ tients were solid organ transplant recipients or had other

Most of the studies assessed liraglutide without an active comparator $(75.3 \% ; N=61)$. The common comparators were exenatide $(N=9)$, sitagliptin or any DPP-4i $(N=8)$, and glimepiride $(N=2)$. The most frequent follow-up duration in the studies was $\geq 12$ months $\quad(N=36), \quad$ followed by $\geq 6-12$ months $\quad(N=27), \quad$ and $<6$ months $(N=13)$. Five studies did not have information on study duration. The treatment serious comorbidities. ${ }^{b}$ Results were reported for overall glucagon-like peptide-1 receptor agonist (no differentiation for liraglutide and exenatide); or data were unavailable in the full-text article. $t i, a b$ title and abstract

effect of liraglutide from outpatient and inpatient settings was reported in 16 and 2 studies, respectively. The remaining abstracts did not specify the treatment setting.

\section{Quality Appraisal of Full-Text Articles}

Findings from the quality appraisal of 43 full-text journal publications are presented in supplementary file 4 . Generally, the study 
designs were appropriate to assess the clinical effectiveness of liraglutide in routine clinical practice. The review findings allow understanding of the outcomes from real-world clinical practice when liraglutide is prescribed according to local guidelines.

Common limitations of some of the studies that were identified included small sample size, missing data, and limited generalizability to the patient setting or study country. Some studies did not adjust for potential confounding by measured and unmeasured factors like prescription bias. Confounding variables such as the use of other medications, baseline severity of disease and duration of diabetes, values of comorbidity indices, baseline prevalence of comorbidities, and body mass index (BMI) were also not addressed between intervention and comparator groups. Notably, these study limitations are typically reported in observational studies [72].

\section{Patient Baseline Characteristics}

In the full-text publications $(N=43), 7413$ patients were treated with liraglutide. The mean age of patients with T2DM on liraglutide treatment was between 43.6 and 63.5 years at baseline. The majority of publications $(N=22)$ included more male patients (50.5-74.4\%) than female patients. In the remaining 21 studies, male patients comprised $29.0-49.4 \%$ of the total study population. Mean duration of T2DM ranged from 5 to 15.8 years. The mean baseline HbA1c level of patients with T2DM before liraglutide treatment was between $7.2 \%$ and 9.8\%. Mean baseline weight and mean BMI were $\quad 63.8-120 \mathrm{~kg}$ and $24.7-38.6 \mathrm{~kg} / \mathrm{m}^{2}$, respectively (see supplementary file 2 ).

The average dosage of liraglutide varied by country (dosage information was not available for 9 publications $[32,35,46,49-51$,
56, 58, 70]). In all the studies from Japan, patients were started at a dosage of $0.3 \mathrm{mg}$ per day and titrated up to $0.9 \mathrm{mg}$ per day in increments of $0.3 \mathrm{mg}$ per week [38, 40, 54, $55,61,68,70]$. The recorded liraglutide dose used in real-world studies was higher in the USA than in Europe, as $1.8 \mathrm{mg}$ was used more often than $1.2 \mathrm{mg}[28,49,56,73]$. In Europe, the use of both 1.2 and $1.8 \mathrm{mg}$ doses of liraglutide was documented. Notably, most of the patients from European studies received liraglutide $1.2 \mathrm{mg}$, and a subgroup of patients in these studies had the dose escalated to $1.8 \mathrm{mg}$.

In studies comparing liraglutide with active comparators, baseline patient characteristics were generally balanced between treatment groups. Some differences were observed in the baseline characteristics, especially regarding use of concomitant and previous antidiabetic therapy. Concomitant SU, MET, and, to an extent, basal/pre-mixed insulin use was similar in patients treated with exenatide or liraglutide. There was insufficient information on the use of concomitant medications in patients using DPP-4i or pioglitazone compared to liraglutide. Information on the use of prior therapies varied between the studies.

Patient characteristics from conference abstracts largely showed a similar trend to those observed for patient baseline characteristics from full-text articles.

\section{Clinical Effectiveness}

\section{Glucose Control}

HbA1c: Change in HbA1c Level The clinical effectiveness of antidiabetic drugs on blood glucose control is measured by HbA1c (which is widely used as a measure of average glucose level over the preceding months before the time of measurement) and/or plasma glucose level (either fasting or post-prandial) [6, 74]. 
The following measurements were reported by the identified observational studies regarding HbA1c level: change in mean HbA1c from baseline to end-of-study, and proportion of patients achieving widely accepted HbA1c targets for patients with T2DM (i.e., $<7 \%$ or $\leq 6.5 \%)$.

One-hundred and six publications reported the changes in HbA1c from baseline to end-of-study, for patients with T2DM treated with liraglutide. Of these, 38 were full-text articles [28-34, 36-53, 55-60, 62, 64, $66,67,69,70]$. Study attributes and patient baseline characteristics from the included studies are provided in supplementary file 2 . Of the 38 full-text publications, 18 studies reported an average follow-up duration of $\geq 12$ months [29-33, 36-40, 42-47], followed by 15 studies with an average follow-up period of $\geq 6-12$ months [34, 48, 49, 52-60, 62, 73]. The remaining five studies had an average follow-up period of $\leq 6$ months $[64,66$, 67, 69, 70].

The identified studies reported mean baseline $\mathrm{HbA} 1 \mathrm{c}$ in the range of $7.5-9.8 \%$ and end-of-study HbA1c ranging from $<6 \%$ to $8.5 \%$ after liraglutide treatment [29-34, 36-50, 52-60, 62, 64, 66, 67, 69, 70]. It was reported that liraglutide therapy led to a mean HbA1c change from baseline of $-0.6 \%$ to $-2.26 \%$ (see Fig. 2). Mean changes in HbA1c from baseline to end-of-study from studies conducted in Europe $(N=21)$, the USA $(N=4)$, and Asia-Pacific $(N=13)$ were $-0.8 \%$ to $-1.9 \%,-0.8 \%$ to $-0.99 \%$, and $-0.6 \%$ to $-2.26 \%$, respectively (see Fig. 2). Real-world studies demonstrate evidence of lowering blood glucose levels regardless of baseline HbA1c level and follow-up durations in patients with T2DM treated with liraglutide (Fig. 2) [28-34, 36-53, 55-60, 62, 64, $66,67,69,70]$.
HbA1c: Proportion of Patients Achieving HbA1c Target of $<7 \%$ and $\leq 6.5 \%$ The guidelines of the ADA (2015) [2] and Canadian Diabetes Association (CDA) suggest multiple goals of therapy, including attaining the composite endpoint of $\mathrm{HbA} 1 \mathrm{c}<7 \%$, no incidence of hypoglycemia, and/or no weight gain (or weight loss if obese) in patients with T2DM. More or less stringent targets may be appropriate if these can be achieved without significant hypoglycemia or AEs. The AACE recommend a stringent glycemic target of HbA1c $\leq 6.5 \%$ with low risk of hypoglycemia [75], which is further endorsed by NICE [74]. A total of 37 publications had data on the proportion of patients achieving the HbA1c targets of $<7.0 \%$ and $\leq 6.5 \%$.

Overall, $29.3-64.5 \% \quad[28-32, \quad 34, \quad 36$, $39,42,43,45,46,48,49,52-54,56-58$, $70,73]$ and $22.05-41.03 \%$ [28, 42, 45, 49, $52,53,56]$ patients with T2DM treated with liraglutide met the $<7 \%$ and $\leq 6.5 \%$ HbA1c targets, respectively (for baseline characteristics of study population in these studies; see supplementary file 2 ).

\section{Fasting and Post-Prandial Plasma}

Glucose Thirty-six publications reported data on the effect of liraglutide on fasting plasma glucose (FPG) and post-prandial plasma glucose (PPG). Of these, 20 were full-text articles. Baseline FPG and PPG levels in patients with T2DM treated in the real-world setting were $114.4-201 \mathrm{mg} / \mathrm{dL}$ and 167.57-252.5 mg/dL, respectively. Overall, the evidence indicated that liraglutide monotherapy and/or in combination with oral glucose-lowering agents was effective in reducing FPG and PPG levels. FPG and PPG reductions from baseline to end-of-study were in the range of 28.1-52.21 and $\quad 23.7-66.71 \mathrm{mg} / \mathrm{dL}, \quad$ respectively. End-of-study FPG and PPG observations 

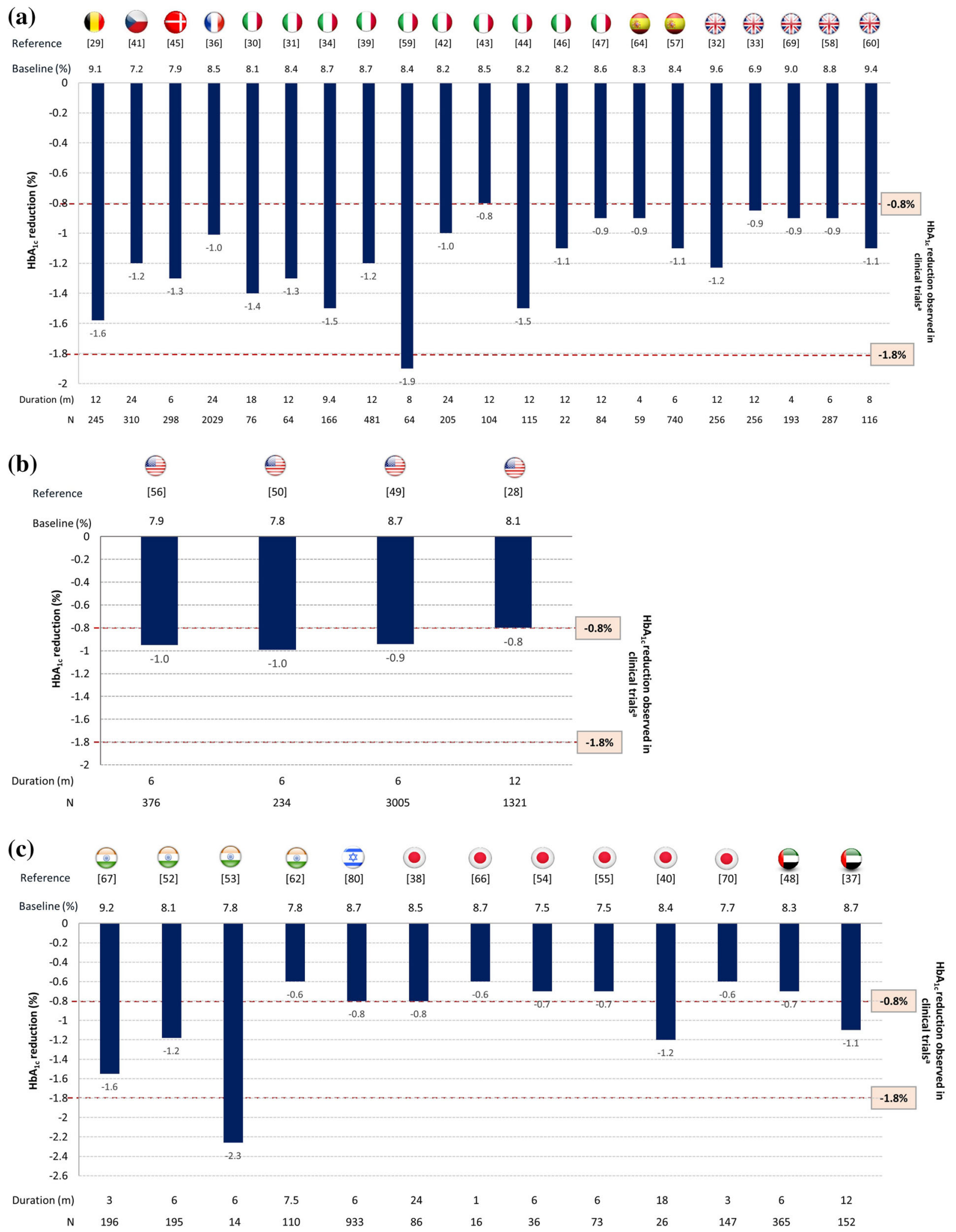
4Fig. 2 Mean change in HbAlc from baseline in patients with T2DM on liraglutide treatment in a Europe $(N=21)$, b the USA $(N=4)$, and c Asia-Pacific $(N=13){ }^{~}{ }^{a}[11-25]$. Note: data in the figures report findings from full-text publications (38 of the 43 articles that were included in the review). Data on HbAlc were not reported in five full-text publications. Numbers in parentheses on the $x$ axis are references to the relevant publications. $H b A 1 c$ glycated hemoglobin, T2DM type 2 diabetes mellitus

ranged from $99.1-144$ and $100.9-180.7 \mathrm{mg} / \mathrm{dL}$, which are close to the ADA-recommended glycemic target for non-pregnant adults (70-130 and $<180 \mathrm{mg} / \mathrm{dL}$, respectively) [76].

\section{Body Weight}

Reduction in body weight is associated with improved glycemic control, insulin sensitivity, and a reduced risk of developing cardiovascular disease in obese patients with diabetes [77].

Seventy-four publications reported effect of liraglutide on body weight in patients with T2DM. Among these, 28 were full-text publications [29-32, 34, 36, 37, 39, 40, 42, 43, $46,48,49,51-55,57-59,62,63,65,67,69]$. Only 4 studies had a follow-up period of $<6$ months $[63,65,67,69]$. The remaining studies were equally divided between study follow-up durations of $\geq 6-12$ months $(N=12)$ $[34,48,49,51-55,57-59,62]$ and $\geq 12$ months $(N=12)$ [29-32, 36, 37, 39, 40, 42, 43, 46, 62].

Overall, liraglutide treatment both as monotherapy and in combination with oral therapy led to significant weight loss in patients with T2DM (Fig. 3). In patients with T2DM who were prescribed liraglutide therapy baseline weight and BMI range were $63.8-120 \mathrm{~kg} / \mathrm{m}^{2}$ and $24.7-38.6 \mathrm{~kg} / \mathrm{m}^{2}$, respectively.

Liraglutide therapy, over time, led to a mean change in absolute weight from baseline of -1.3 to $-8.65 \mathrm{~kg}$. Mean changes in weight from baseline in patients from Europe $(N=16)$, the USA $(N=1)$, and Asia-Pacific $(N=11)$ were
-2.4 to $-6.5 \mathrm{~kg},-2.9 \mathrm{~kg}$, and -1.3 to $-8.7 \mathrm{~kg}$, respectively (Fig. 3). A few studies showed mean weight reduction in patients with T2DM for up to 2 years after initiating liraglutide treatment [30, 40, 42, 43, 78].

Two studies that included 3210 patients showed that patients experienced reduction in body weight regardless of their baseline BMI $\left(25.0-40.0 \mathrm{~kg} / \mathrm{m}^{2}\right)$ after initiating liraglutide therapy [42, 49]. Importantly, higher baseline BMI was associated with larger absolute weight loss in patients [42, 49]. Chitnis et al. [49] ( $N=3005$ patients) reported larger weight reductions with increasing $\mathrm{BMI}$ at the 6-month follow-up (BMI $\geq 40 \mathrm{~kg} / \mathrm{m}^{2}:-4.0 \mathrm{~kg}$; BMI $35-39.9 \mathrm{~kg} / \mathrm{m}^{2}$ : $-3.0 \mathrm{~kg}$; BMI $30-34.9 \mathrm{~kg} /$ $\mathrm{m}^{2}: \quad-1.9 \mathrm{~kg} ; \quad$ BMI $25-29.9 \mathrm{~kg} / \mathrm{m}^{2}:-1.5 \mathrm{~kg}$; $P<0.01$ for trend) [49]. Ponzani et al. [42] ( $N=205$ patients) reported similar findings at 20 months $\quad\left(B M I \geq 35 \mathrm{~kg} / \mathrm{m}^{2}\right.$ : $\quad-6.66 \mathrm{~kg}$; BMI $>30-35 \mathrm{~kg} / \mathrm{m}^{2}$ : $\quad-4.8 \mathrm{~kg} ; \quad \mathrm{BMI} \leq 30 \mathrm{~kg} / \mathrm{m}^{2}$ : $-2.98 \mathrm{~kg}$ ) [42]. Both these studies had good generalizability to real-world patients with T2DM and obesity [42, 49]. These findings reinforce that liraglutide could be beneficial, not only in avoiding weight gain, but also in helping patients with T2DM and obesity to lose weight.

\section{NICE Composite Endpoint: Percentage of Patients with HbA1c Reduction $\geq 1 \%$ and Weight Reduction $\geq 3 \%$}

Treatment guidelines for the management of T2DM highlight the importance of not only improving glycemic control but also of managing obesity and hypertension [74]. Thus, composite endpoints are increasingly reported in the assessment of novel diabetes therapies. The NICE guidelines recommend that GLP-1 mimetic therapy is continued if patients with T2DM have a beneficial metabolic response (a reduction of at least $11 \mathrm{mmol} / \mathrm{mol}$ 


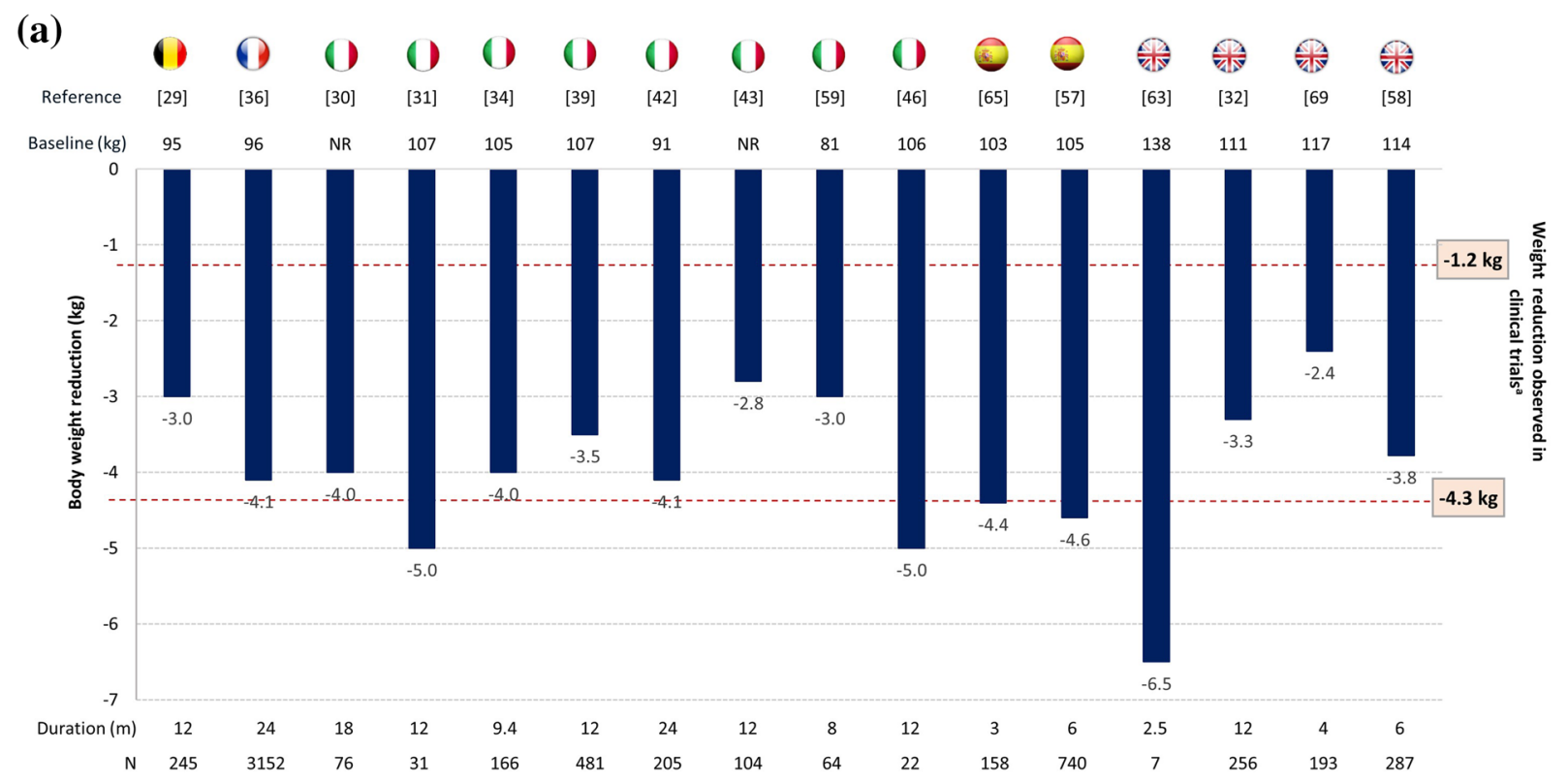

(b)
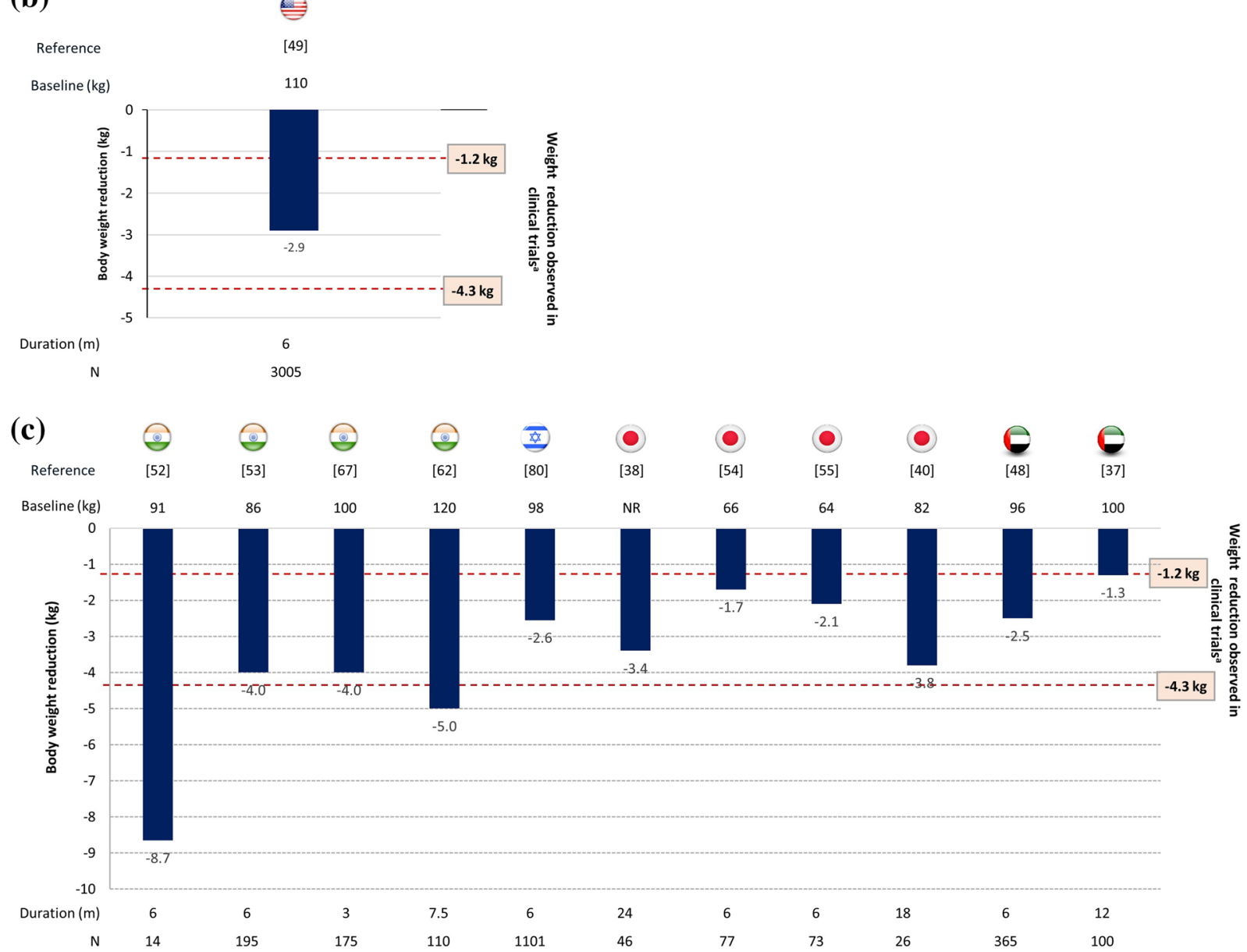
4Fig. 3 Mean reduction in weight from baseline in patients with T2DM on liraglutide treatment in a Europe $(N=16)$, b the USA $(N=1)$, and c Asia-Pacific $(N=11){ }^{2}{ }^{a}[11-25]$. Note: data in the figure report findings from 28 full-text publications (28 of the 43 articles that were included in the review). Data on weight were not reported in 15 full-text publications. Numbers in parentheses on the $x$ axis are references to the relevant publications. T2DM type 2 diabetes mellitus

[1.0\%] in HbA1c and a weight loss of at least 3\% of initial body weight in 6 months) [74].

Nine full-text articles reported data on patients achieving the NICE composite endpoint with liraglutide therapy (Table 2). These studies reported that the NICE composite endpoint was met in $20.1 \%$ (baseline HbA1c: 9.7\% [51]) to 47.0\% (baseline HbA1c: $8.2 \%$ [44]) of patients with T2DM who were treated with liraglutide for at least 6 months.

Treatment with DPP-4i resulted in higher proportions of patients meeting the NICE composite endpoint (57-64\%; baseline HbA1c: $8.1 \%)$ compared to liraglutide (28-32\%; baseline HbA1c: 9.6\%) and exenatide (21-24\%; baseline HbA1c: 9.8\%) [32, 33]. Notably, in these studies baseline HbA1c level of patients with T2DM was significantly different. In two other studies, despite similar baseline characteristics of patients, superior HbA1c and weight reductions with liraglutide compared to sitagliptin were reflected in routine clinical practice (25\% vs. $10 \%$, respectively) [58, 79]. Data from conference abstracts mirrored these findings.

\section{Comparative Effectiveness}

Data from studies comparing liraglutide with an active comparator (sitagliptin or DPP-4i, exenatide or GLP-1 RA, pioglitazone or TZD, glimepiride or SU, and MET) were reported in eight full-text articles (Table 3). Comparative effectiveness data on the effect of liraglutide on blood pressure, lipid profile, FPG, and PPG were available from a small number of studies.

\section{Change in HbA1c Level}

An overview of the changes in the post-interventional mean HbA1c level achieved by liraglutide treatment compared to other antidiabetic therapies is given in Table 3. Overall, studies comparing liraglutide and sitagliptin showed that liraglutide patients are more likely to achieve HbA1c and weight reductions compared with sitagliptin/DPP-4i patients in routine clinical practice. Change in mean HbA1c level with liraglutide treatment was greater than that observed with sitagliptin or DPP-4i treatment $[32,33,40,45,56,58]$. A retrospective database analysis in primary care using the Clinical Practice Research Datalink in the UK assessed the effectiveness of liraglutide treatment in patients aged $\geq 18$ years [58]. This study showed superior HbA1c and weight reductions with liraglutide compared to sitagliptin. When controlling for potential confounders, liraglutide was more likely than sitagliptin to achieve an HbA1c reduction of $\geq 1 \% \quad$ odds ratio $\quad(\mathrm{OR})=2.29, \quad 95 \%$ confidence interval (CI): 1.62-3.25], the composite target of $\mathrm{HbA} 1 \mathrm{c}$ reduction $\geq 1 \%$ and weight reduction $\geq 3 \% \quad(\mathrm{OR}=2.99 ; 95 \% \quad \mathrm{CI}$ : 2.00-4.48), and a target $\mathrm{HbA} 1 \mathrm{c}<7 \%$ $(\mathrm{OR}=2.11 ; 95 \% \mathrm{CI}: 1.45-3.07)$ after 6 months of treatment [58]. In another retrospective chart audit conducted in the UK, greater changes in HbA1c were seen with liraglutide $(-1.28 \%)$ in comparison with a pooled group of DPP-4i $(-0.74 \% ; P<0.05)$ [32]. In the same study, a subgroup analysis was conducted for patients switching to liraglutide from DPP-4i which resulted in a mean $\mathrm{HbA1c}$ reduction of $-0.9 \%$ for the liraglutide-treated patients $(P<0.05$ vs. DPP-4i) [32]. Importantly, patients 
Table 2 Overview of studies reporting NICE Composite endpoint in real-world evidence studies

\begin{tabular}{|c|c|c|c|c|c|}
\hline Code & Intervention & $\begin{array}{l}\text { Mean baseline } \\
\text { HbA1c (SD), \% }\end{array}$ & $N$ & $\begin{array}{l}\text { Follow-up } \\
\text { duration } \\
\text { (months) }\end{array}$ & $\begin{array}{l}\text { NICE composite } \\
\text { endpoint }^{b} \text { achieved }\end{array}$ \\
\hline \multicolumn{6}{|c|}{ Full-text publications } \\
\hline \multirow[t]{2}{*}{$\begin{array}{l}\text { Nyeland et al. } \\
2015[58]\end{array}$} & Liraglutide & $8.8(1.9)$ & 287 & 6 & $25.10 \%$ \\
\hline & Sitagliptin & $8.6(1.5)$ & 2781 & & $10.4 \%^{\mathrm{a}}$ \\
\hline $\begin{array}{l}\text { Heymann et al. } \\
2014[51]\end{array}$ & Liraglutide & 9.7 (NA) & 1101 & 6 & $20.10 \%$ \\
\hline $\begin{array}{c}\text { Russo et al. } \\
2015 \text { [44] }\end{array}$ & Liraglutide & $8.2(1.3)$ & 115 & 12 & $47 \%$ \\
\hline \multirow{3}{*}{$\begin{array}{c}\text { Evans et al. } \\
2014 \text { [33] }\end{array}$} & Liraglutide & $9.6(0.5)$ & 229 & 12 & $32 \%$ \\
\hline & Exenatide & $9.8(0.8)$ & 148 & & $24 \%$ \\
\hline & DPP-4i & $8.1(0.4)$ & 710 & & $64 \%$ \\
\hline \multirow{15}{*}{$\begin{array}{l}\text { Evans et al. } \\
2013 \text { [32] }\end{array}$} & Exenatide BID & $9.6(0.5)$ & 148 & 12 & 3 months: $27 \%$ \\
\hline & & & & & 6 months: $24 \%$ \\
\hline & & & & & 9 months: $26 \%$ \\
\hline & & & & & 12 months: $25 \%$ \\
\hline & & & & & Audit end: $21 \%$ \\
\hline & Liraglutide & $9.8(0.8)$ & 256 & & 3 months: $35 \%$ \\
\hline & & & & & 6 months: $32 \%$ \\
\hline & & & & & 9 months: $31 \%$ \\
\hline & & & & & 12 months: $29 \%$ \\
\hline & & & & & Audit end: $28 \%$ \\
\hline & DPP-4i (sitagliptin, & $8.1(0.4)$ & 710 & & 3 months: $59 \%$ \\
\hline & saxagliptin, or & & & & 6 months: $61 \%$ \\
\hline & vildagliptin) & & & & 9 months: $52 \%$ \\
\hline & & & & & 12 months: $54 \%$ \\
\hline & & & & & Audit end: $57 \%$ \\
\hline \multicolumn{6}{|c|}{ Conference abstracts } \\
\hline $\begin{array}{l}\text { Heymann et al. } \\
2013[80]\end{array}$ & Liraglutide & $8.7(1.3)$ & 453 & 6 & $20.10 \%$ \\
\hline $\begin{array}{l}\text { Karasik et al. } \\
2013[81]\end{array}$ & Liraglutide & $8.57(1.20)$ & 614 & 6 & $16.90 \%$ \\
\hline $\begin{array}{l}\text { Fatima et al. } \\
2014[82]\end{array}$ & Liraglutide & 8.7 (NA) & 43 & 6 & $42 \%$ \\
\hline
\end{tabular}


Table 2 continued

\begin{tabular}{|c|c|c|c|c|c|}
\hline Code & Intervention & $\begin{array}{l}\text { Mean baseline } \\
\text { HbAlc (SD), \% }\end{array}$ & $N$ & $\begin{array}{l}\text { Follow-up } \\
\text { duration } \\
\text { (months) }\end{array}$ & $\begin{array}{l}\text { NICE composite } \\
\text { endpoint }^{b} \text { achieved }\end{array}$ \\
\hline \multirow{2}{*}{$\begin{array}{l}\text { Mattson et al. } \\
2015 \text { [79] }\end{array}$} & Liraglutide & $7.69(1.43)$ & 180 & 6 & $27 \%$ \\
\hline & Sitagliptin & $7.53(1.50)$ & 208 & & $10 \%$ \\
\hline
\end{tabular}

$B I D$ twice daily, $D P P-4 i$ dipeptidyl peptidase-4 inhibitor, $H b A l c$ glycated hemoglobin, $N$ number of patients, $N A$ not available, NICE National Institute for Health and Care Excellence, $S D$ standard deviation

a $P<0.001$

b Percentage of patients with $\mathrm{HbAlc}$ reduction $\geq 1 \%$ and weight reduction $\geq 3 \%$

using GLP-1 RA (62.5\%) had a higher baseline BMI score and HbA1c values, and longer diabetes duration than those on DPP-4i [32]. In other studies, it was also observed that patients with T2DM were switching their antidiabetic treatment from DPP-4i to liraglutide [37, 51]. This likely reflects the superior effect of GLP-1 RA therapy compared with DPP-4i, and emphasizes the success of switching patients from a DPP- $4 \mathrm{i}$ to a GLP-1 RA [83, 84].

Four studies compared the glycemic effect of liraglutide and exenatide. Overall, change in HbA1c with liraglutide was slightly greater than that observed with exenatide [32, 33, 45, 50] (Table 3). Half of the studies reported statistically significant reductions in HbA1c level with liraglutide treatment compared to exenatide. Notably, patients previously receiving exenatide achieved a $0.8 \%$ HbA1c reduction from baseline when switched to liraglutide, in excess of the $0.32 \%$ reduction from baseline seen in the clinical trial switching exenatide to liraglutide. However, this may reflect suboptimal previous exenatide therapy, as the majority of these patients $(62.6 \%)$ discontinued exenatide due to tolerability issues [85].

Percentage of Patients Achieving HbA1c Recommended Targets of $<7 \%$ and $\leq 6.5 \%$ Four studies reported comparative data for percentage of patients achieving recommended HbA1c targets [30, 50, 56, 58], details of which are provided in Table 3. Liraglutide showed better effectiveness in achieving a higher percentage of patients reaching the $<7 \%$ HbA1c goal compared to glimepiride at 18 months $(51.3 \%$ vs. $11.6 \%$; $P<0.001)$ [30] and compared to sitagliptin $(29.3 \% \quad$ vs. $\quad 22.8 \% ; \quad$ OR $=2.11, \quad 95 \% \mathrm{CI}$ 1.45-3.07) [58]. Superior effectiveness of liraglutide compared to sitagliptin was also reported $(52 \%$ vs. $44 \%$; 6 months; OR $=1.55$; $P<0.01$ ) [56]. Using the HbA1c target of $\leq 6.5 \%$, liraglutide treatment also resulted in a higher proportion of patients achieving the target compared to sitagliptin (37 vs. $26 \%$; $\mathrm{OR}=2.00 ; P<0.01)$ [56].

Glucose-lowering effectiveness was comparable between liraglutide and exenatide therapy. The percentage of patients reaching $<7 \%$ HbA1c target was reported as $64.5 \%$ and $54.4 \%$ after 6 months of therapy with liraglutide and exenatide treatment, respectively $(P=0.04)$ [50].

Body Weight Five studies provided comparative data on the weight effect of liraglutide treatment (Table 3) [30, 32, 33, 40, 58]. Overall, these findings demonstrated an added benefit of liraglutide therapy in achieving HbA1c and weight reductions compared with other diabetic 


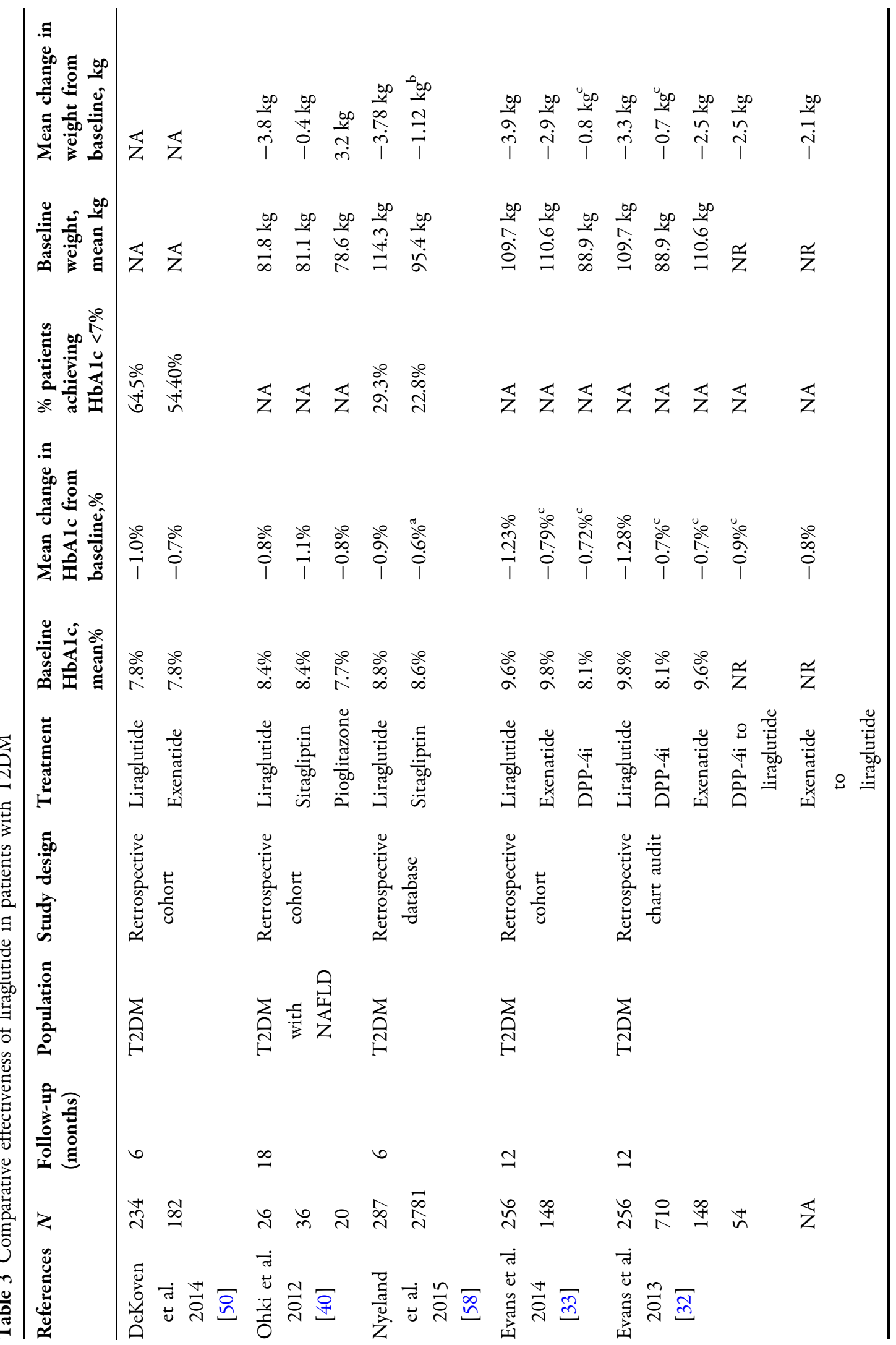




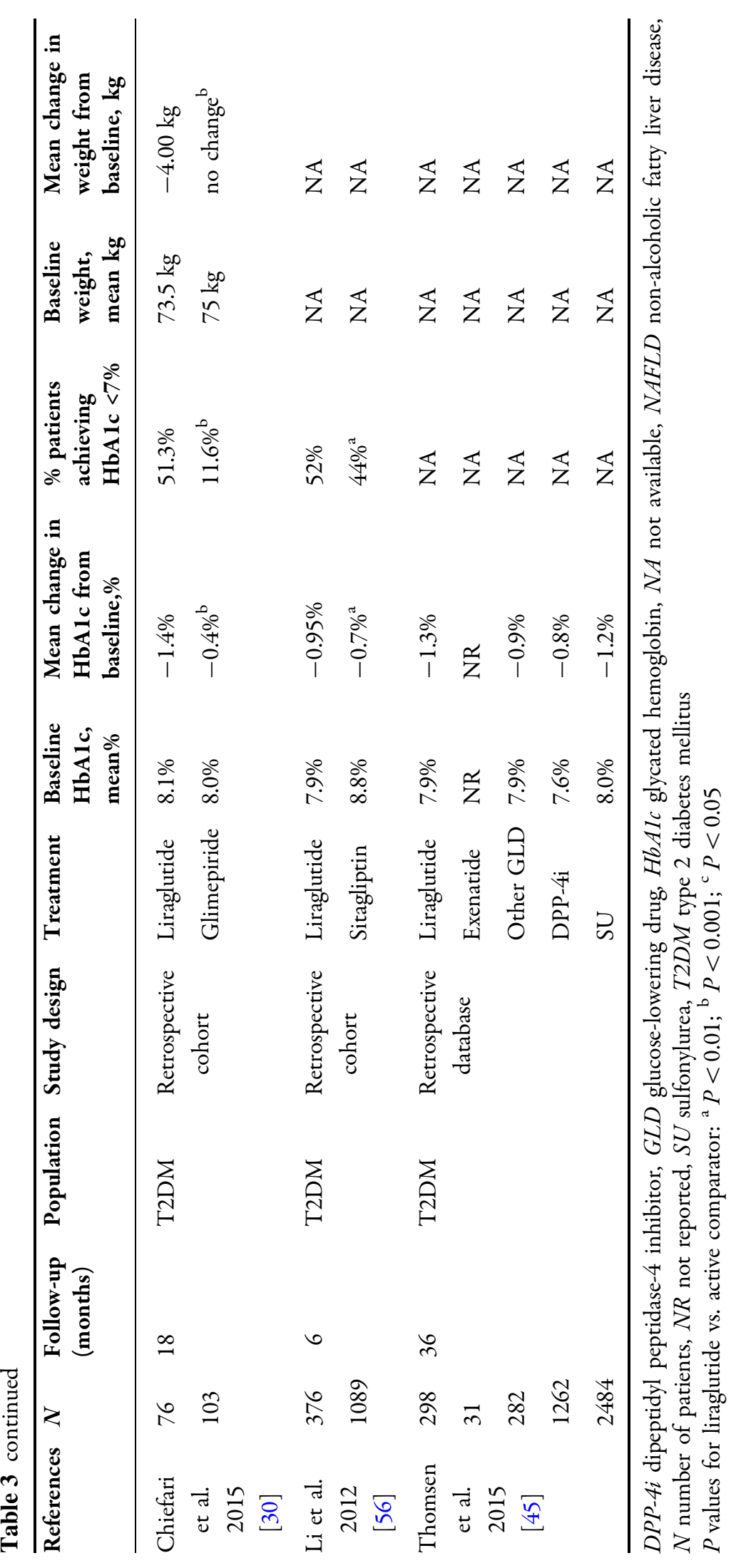


therapies in real-world setting. Liraglutide showed superior weight reduction compared to sitagliptin [58], pioglitazone [40], and glimepiride [30]. Furthermore, liraglutide was effective in reducing patients' weight among those with previous therapy with insulin [62] or a DPP-4i class drug [32].

Clinical effectiveness regarding body weight reduction was comparable between liraglutide and exenatide, though liraglutide usually led to a numerically higher body weight reduction $[32,86]$.

\section{Tolerability and Safety}

\section{Overall}

A total of 52 publications that were identified in the literature search reported data on the $\mathrm{AE}$ profile of liraglutide. Of these, 26 were full-text articles. The rates of any $\mathrm{AE}$ ranged from $0.0 \%$ to $64.3 \%$. Gastrointestinal AEs (nausea, vomiting, diarrhea, abdominal pain) were the most commonly reported AE type $(0.51-42.9 \%$ of all reported AEs). Gastrointestinal AEs were normally reported in the first few weeks after initiating liraglutide and when present, were considered mild and transient. Skin reactions/rash and headache were uncommon (1-3\%). Up to one-third of patients withdrew from the studies because of AEs (0-30\%) [29, 36, 37, 39, 41, 44, $47,48,52,54,55,57,62,64,67]$. The most common reasons for withdrawal due to AEs were reported to be vomiting and nausea. From the identified full-text publications, to our knowledge only four studies reported occurrences of pancreatic disease $[29,36,37,42]$ and one study reported thyroid disease [36]. Two studies reported no cases of pancreatic disease [29, 42]. Ghuman et al. [37] reported 1 case of pancreatitis among 152 patients that were followed for up to 20 months. In the EVIDENCE study (ClinicalTrials.gov identifier: NCT01226966), 3152 patients were followed up to 24 months [36], in that period 8 medical AEs related to pancreatic pathologies (pancreatitis $[N=1]$, acute pancreatitis $[N=4]$, increased lipasemia $[N=1]$, and hepato-pancreatic biological disorder $[N=1]$ ) and eight AEs linked to thyroid pathologies (goiter $[N=2]$, hyperthyroidism $[N=1]$, hypothyroidism $[N=1]$, thyroid disorder $[N=1]$, thyroid nodule $\quad[N=1], \quad$ thyroid cancer [non-encapsulated papillary carcinoma; $N=1$ ], and thyroidectomy with no known etiology $[N=1]$ ) were reported. In this observational study, one patient died of pancreatic tumor 4 months after starting treatment with liraglutide. Funch et al. [35] assessed the relationship between liraglutide and acute pancreatitis or pancreatic cancer in a post-marketing safety assessment program and reported no increased risk for acute pancreatitis or pancreatic cancer in association with liraglutide therapy. Hyperglycemic events were not reported in any of the publications covered by this review.

\section{Hypoglycemia}

Twenty-six publications reported data on hypoglycemia (Table 4). Of these, 17 were full-text articles. Data from full-text articles showed that hypoglycemia-related events, including minor hypoglycemia, occurred at low rates $(0.0-15.2 \%)$. Symptomatic hypoglycemia occurred in $0.8 \%$ of patients with liraglutide treatment and the occurrence of major (severe) hypoglycemia was rare. In patients who received liraglutide monotherapy, the rate of episodes of hypoglycemia did not exceed $0.8 \%$. 
Table 4 Occurrence of hypoglycemia

\begin{tabular}{|c|c|c|c|c|}
\hline References & $\begin{array}{l}\text { Intervention } \\
\text { (concomitant } \\
\text { medication) }\end{array}$ & $\begin{array}{l}\text { Follow-up } \\
\text { duration }\end{array}$ & $N$ & Hypoglycemic episodes \\
\hline \multirow{2}{*}{$\begin{array}{l}\text { Gautier et al. } \\
2015[36]\end{array}$} & \multirow[t]{2}{*}{ Liraglutide (OADs) } & \multirow[t]{2}{*}{24 months } & 3152 & 3 months: $7.4 \%$ \\
\hline & & & $\begin{array}{c}2 \text { years: } \\
2009\end{array}$ & 2 years: $4.4 \%$ \\
\hline $\begin{array}{l}\text { Toyoda et al. } \\
2014[61]\end{array}$ & Liraglutide (SU) & 6 months & 380 & $0.0 \%$ \\
\hline \multirow[t]{8}{*}{$\begin{array}{l}\text { Mori et al. } 2011 \\
\quad[68]\end{array}$} & Liraglutide (OADs) & \multirow[t]{8}{*}{ NA } & \multirow[t]{4}{*}{8} & $\begin{array}{l}\% \text { time in hypoglycemia }(24-\mathrm{h}) \text { at pre-treatment: } 0.1 \\
(0.3) \%\end{array}$ \\
\hline & $0.3 \mathrm{mg}$ & & & \% time in hypoglycemia (24-h): $0.5(1.7) \%$ \\
\hline & $0.6 \mathrm{mg}$ & & & $\%$ time in hypoglycemia (24-h): $0.1(0.2) \%$ \\
\hline & $0.9 \mathrm{mg}$ & & & \% time in hypoglycemia (24-h): $0.4(1.3) \%$ \\
\hline & Liraglutide only & & \multirow[t]{4}{*}{12} & $\%$ time in hypoglycemia $(24-\mathrm{h}): 0.0(0.0) \%$ \\
\hline & $0.3 \mathrm{mg}$ & & & \% time in hypoglycemia $(24-\mathrm{h}): 0.0(0.1) \%$ \\
\hline & $0.6 \mathrm{mg}$ & & & $\%$ time in hypoglycemia $(24-\mathrm{h}): 0.0(0.0) \%$ \\
\hline & $0.9 \mathrm{mg}$ & & & $\%$ time in hypoglycemia $(24-\mathrm{h}): 0.0(0.0) \%$ \\
\hline $\begin{array}{l}\text { Usui et al. } 2013 \\
\text { [70] }\end{array}$ & Liraglutide (SU) & 3 months & 147 & $0.0 \%$ \\
\hline \multirow{2}{*}{$\begin{array}{l}\text { Li et al. } 2014 \\
\text { [56] }\end{array}$} & Liraglutide (OADs) & \multirow[t]{2}{*}{6 months } & 376 & Severe: $0.5 \%$ \\
\hline & Sitagliptin (OADs) & & 1089 & Severe: $0.61 \%(P=0.81$; between groups $)$ \\
\hline \multirow{5}{*}{$\begin{array}{l}\text { Mezquita-Raya } \\
\text { et al. } 2015 \text { [57] }\end{array}$} & \multirow[t]{5}{*}{ Liraglutide (OADs) } & \multirow[t]{5}{*}{6 months } & \multirow[t]{5}{*}{740} & All: $7.8 \%$ \\
\hline & & & & Severe: $0.0 \%$ \\
\hline & & & & Patients with insulin plus liraglutide: $10.6 \%$ \\
\hline & & & & $\begin{array}{l}\text { Patients with secretagogues plus liraglutide: } 15.2 \% \\
(P=0.369 \text { vs. insulin plus liraglutide })\end{array}$ \\
\hline & & & & $\begin{array}{l}\text { Patients with MET plus liraglutide: } 1.6 \%(P<0.001 \\
\text { vs. insulin/secretagogues plus liraglutide })\end{array}$ \\
\hline \multirow{2}{*}{$\begin{array}{l}\text { Buysschaert et al. } \\
2015 \text { [29] }\end{array}$} & \multirow{2}{*}{$\begin{array}{l}\text { Liraglutide (MET and } \\
\text { SU) }\end{array}$} & \multirow[t]{2}{*}{12 months } & \multirow[t]{2}{*}{245} & Minor: 0.07 to 0.55 events per patient per month \\
\hline & & & & Major: 1 event at 3 months \\
\hline $\begin{array}{l}\text { Kesavadev et al. } \\
2012[53]\end{array}$ & Liraglutide (OADs) & 6 months & 14 & $0.0 \%$ \\
\hline $\begin{array}{l}\text { Mulligan et al. } \\
2013 \text { [69] }\end{array}$ & $\begin{array}{l}\text { Liraglutide (SU; } \\
\text { insulin) }\end{array}$ & 4 months & 193 & $\begin{array}{l}\text { Minor: } 5.7 \% \text { ( } 81.8 \% \text { on concomitant SUs; } 0.09 \% \\
\text { patients on basal insulin) }\end{array}$ \\
\hline $\begin{array}{l}\text { Chitnis et al. } \\
2014 \text { [49] }\end{array}$ & Liraglutide only & 6 months & 3005 & $0.2-0.7 \%$ \\
\hline
\end{tabular}


Table 4 continued

\begin{tabular}{|c|c|c|c|c|}
\hline References & $\begin{array}{l}\text { Intervention } \\
\text { (concomitant } \\
\text { medication) }\end{array}$ & $\begin{array}{l}\text { Follow-up } \\
\text { duration }\end{array}$ & $N$ & Hypoglycemic episodes \\
\hline $\begin{array}{l}\text { Cotugno et al. } \\
2015[31]\end{array}$ & Liraglutide only & 12 months & 31 & $0.0 \%$ \\
\hline \multirow{3}{*}{$\begin{array}{l}\text { Evans et al. } 2014 \\
\text { [33] }\end{array}$} & Liraglutide only & 12 months & 256 & Symptomatic: $0.8 \%$ \\
\hline & Exenatide & & 148 & Symptomatic: $0.9 \%$ \\
\hline & DDP-4i & & 710 & Symptomatic: $0.8 \%$ \\
\hline \multirow{2}{*}{$\begin{array}{l}\text { Vitagliano et al. } \\
2014[46]\end{array}$} & BS & 12 months & 28 & Symptomatic reactive: $28.5 \%$ \\
\hline & Liraglutide only & & 22 & $0.0 \%$ \\
\hline \multirow{3}{*}{$\begin{array}{l}\text { Evans et al. } 2013 \\
\text { [32] }\end{array}$} & DPP-4i & 12 months & 710 & Symptomatic: $0.8 \%$ \\
\hline & Exenatide & & 148 & Symptomatic: $0.9 \%$ \\
\hline & Liraglutide only & & 256 & Symptomatic: $0.8 \%$ \\
\hline $\begin{array}{l}\text { Kaur et al. } 2014 \\
\text { [67] }\end{array}$ & Liraglutide (OADs) & 3 months & 196 & Minor: $3.0 \%$ \\
\hline $\begin{array}{l}\text { Lapolla et al. } \\
2015 \text { [39] }\end{array}$ & Liraglutide (OADs) & 12 months & 481 & $5.0 \%$ \\
\hline \multirow[t]{2}{*}{$\begin{array}{l}\text { Chiefari et al. } \\
2015 \text { [30] }\end{array}$} & $\begin{array}{l}\text { Liraglutide (MET, } \\
\text { MET plus insulin) }\end{array}$ & 18 months & 76 & $\begin{array}{l}\text { Major: } 0.0 \% \\
\text { Minor: } 2.6 \%\end{array}$ \\
\hline & Glimepiride & & 103 & $\begin{array}{l}\text { Major: } 2.9 \%, P=0.263 \text { (between groups) } \\
\text { Minor: } 18.4 \%, P<0.001 \text { (between groups) }\end{array}$ \\
\hline
\end{tabular}

$D P P-4 i$ dipeptidyl peptidase- 4 inhibitor, $M E T$ metformin, $N$ number of patients, $O A D$ oral antidiabetic drug, $S U$ sulfonylurea

OptumInsight ${ }^{\mathrm{TM}}$ and HealthCore ${ }^{\circledR}$ are two major US healthcare companies' administrative claims databases

Hypoglycemia was more often reported in studies with liraglutide combination therapy. Nineteen studies reported hypoglycemia episodes most frequently when liraglutide was added to MET, SU, insulin, or other OADs (0.0-15.2\%).

Overall results from conference abstracts echoed the conclusions from full-text publications.

Data from comparative studies showed similar rates of hypoglycemia in all treatment groups, except for glimepiride compared to liraglutide $(18.4 \%$ vs. $2.9 \%$; $P<0.001)$ [30]. Rates of hypoglycemia did not vary at different follow-up durations. A real-world study [36] that followed patients with T2DM who were on liraglutide treatment for 24 months reported a hypoglycemia rate of $4.4 \%(N=2009$ patients) [36]. Notably, no correlation between the occurrence of hypoglycemia and liraglutide dosage $(1.2 \mathrm{mg}$ or $1.8 \mathrm{mg}$ ) was observed [36]. 


\section{DISCUSSION}

This systematic review reports evidence of the effectiveness of liraglutide in T2DM treatment in real-world clinical practice. The main findings presented in this review were obtained from full-text journal articles. The results of the identified conference proceedings in the last 3 years were consistent with those of full text articles.

Overall, liraglutide was demonstrated to be an effective (i.e., reduced HbA1c and body weight) treatment for patients with T2DM. Clinical effectiveness of liraglutide treatment was shown in patients at T2DM with continued liraglutide therapy (at least 12 months), and was well tolerated in these patients in real-life clinical practice.

\section{Glucose Control}

Real-life use of liraglutide confirmed good control of HbA1c level among patients with T2DM (7413 patients treated with liraglutide), measured by absolute change of HbA1c level, the percentage of patients reaching $\mathrm{HbA1c}$ treatment target $(<7 \%$ or $\leq 6.5 \%)$, and the NICE composite endpoint. In real-world clinical practice, liraglutide treatment (alone or in combination with other glucose-lowering therapies) significantly reduces HbA1c (change in mean HbA1c: $-0.9 \%$ to $-2.26 \%)$. This change in HbA1c was clinically relevant and corresponded well with that reported in the randomized controlled trials (RCTs; $-0.8 \%$ to $-1.83 \%)$ [11-25]. Among the included studies, at least one-third of patients on liraglutide therapy reached the $\mathrm{HbA} 1 \mathrm{c}<7.0 \%$ target (29.5-65.0\%), which is comparable to the proportion (35.0-45.0\%) of patients reaching the HbA1c target reported after 26 weeks of liraglutide treatment in the LEAD RCTs [11-16].
The beneficial effect of liraglutide treatment on FPG and PPG in patients with T2DM was also demonstrated in the real-world setting.

The NICE composite endpoint was met in $16.90-47.0 \%$ of patients with T2DM who initiated liraglutide therapy in real-life clinical practice. The average decrease in $\mathrm{HbA1c}$ was approximately $1 \%$ regardless of baseline $\mathrm{HbA} 1 \mathrm{c}$ level. We identified 3 studies, with a total of 268 patients treated with liraglutide, investigating the effectiveness of liraglutide using different doses of $(0.3-1.8 \mathrm{mg})$ [43, 57, 68], which also reflects the choice of doses in different countries. Based on this limited number of patients, it seems that HbA1c change from baseline to post-intervention does not differ substantially between different doses [43, 57]. However, escalating liraglutide dose to $1.8 \mathrm{mg}$ in patients who do not respond to the $1.2 \mathrm{mg}$ dose resulted in an additional decrease in HbA1c $(-0.62 \% \pm 0.17 \% ; \quad P<0.05 \quad$ vs. $\quad$ liraglutide $1.2 \mathrm{mg}$ ) [43]. Dose escalation to $1.8 \mathrm{mg}$ also helped further body weight reduction [43].

\section{Body Weight}

Real-world studies showed substantial changes in body weight ( -1.3 to $-8.65 \mathrm{~kg}$ ). Studies showed that patients experienced reduction in body weight regardless of their baseline BMI $\left(25.0-40.0 \mathrm{~kg} / \mathrm{m}^{2}\right)$ after initiating liraglutide therapy [42, 49]. In addition to this, higher BMI at baseline was associated with slightly greater weight loss with liraglutide treatment $[42,49]$. The effect of such weight loss in patients with T2DM remains to be demonstrated; however, this finding reveals that liraglutide may help in improving patient quality of life in patients with T2DM with overweight or obesity $[42,49]$. Statistically significant and numerically larger reductions in BMI were demonstrated. 
It is important to note that both glycemic control and weight effect of liraglutide in patients with T2DM were maintained with at least 12 months of liraglutide treatment $[29,38,39,42,45,49,78]$.

\section{Comparative Effectiveness}

Our review identified a few studies which showed a beneficial effect of liraglutide both in terms of glycemic and weight control when patients switched from DPP-4i [32, 37, 51]. Generally, liraglutide achieved better reductions in HbA1c and weight control in patients with T2DM compared with continuing DPP-4i/sitagliptin [58, 79], exenatide [32, 33], glimepiride, and pioglitazone.

\section{Safety}

The safety profile of liraglutide was assessed based on the systematic literature search that included effectiveness outcomes as primary endpoints. Overall, the safety profile of liraglutide assessed in this review of real-world studies was observed to be in line with what is reported in the summary of product characteristics (SmPC) for liraglutide [87]. The occurrence of acute pancreatitis reported in the EVIDENCE study $(0.1 \%)$ is in agreement with the SmPC for liraglutide $(<0.2 \%)$ [87]. The findings in this review confirm that liraglutide could be safely used in real-world clinical practice also in combination with other OADs. The safety data corroborate findings from clinical trials of liraglutide [88, 89] (AEs ranged from $0.0 \%$ to $64.3 \%$ in real-world observational studies compared to $33.0-56.0 \%$ in the LEAD RCTs) [11-16]. Safety findings were also in line with other RCTs assessing liraglutide [17-25]. For a detailed assessment of the real-world safety profile of liraglutide, a new systematic literature search specifying safety specific outcomes would be needed as this was not within the scope of the present review.

\section{Biases and Confounding Factors in Observational Studies}

Although this review found comparable effectiveness and safety profile of liraglutide in the real-world and RCT settings, it is important to note the difference in patient groups in observational studies and the LEAD trials with regard to patient baseline characteristics such as duration of T2DM, baseline Hba1c level, and BMI. Compared to the disease duration of patients enrolled in the LEAD trials (5.2-9.0 years), the average duration of T2DM in patients in real-world setting was longer (5-15.8 years), suggesting that patients were in a slightly later stage of T2DM. The LEAD program showed that liraglutide works in the continuum of T2DM, and may provide greater benefit when used earlier in the course of disease progression [11-16]. Additionally, patients with T2DM in the real-world setting had a higher baseline HbA1c (7.5-9.8\%) and BMI $\left(24.7-38.6 \mathrm{~kg} / \mathrm{m}^{2}\right)$ compared to the LEAD clinical trials (baseline HbA1c: 8.1-8.6\%; and baseline BMI: $29.8-33.5 \mathrm{~kg} / \mathrm{m}^{2}$ ) [88], suggesting more severe disease and overweight/obesity in T2DM real-world setting. Thus, liraglutide is likely to show better clinical effectiveness in real-world studies than that reported in RCTs if used in patient groups with similar disease duration and baseline disease severity.

\section{Merits and Limitations of This Review}

This systematic literature review conducted according to NICE guidelines is the first of its kind to summarize evidence on the real-world use of liraglutide. Merits of this systematic 
literature review include its a priori design—set inclusion and exclusion criteria, parallel screening review performed independently by two reviewers, and stringent quality control and assessment. All the parameters and clinical endpoints (i.e., HbA1c thresholds) reported were consistent with those used in clinical trials. Most of the studies were of good quality based on the quality assessment of the study design and methodology. The reporting quality of the full-text journal articles was consistent in relation to endpoints and use of liraglutide. There were a few drawbacks with the quality of the included studies. The majority of studies included in this review had a moderate sample size and were based on existing data. Most of the studies were also designed as non-comparative studies and need to be interpreted carefully as they might present some limitations in terms of bias and confounding. Despite these limitations, a similar pattern showing benefits of liraglutide on HbA1c and weight is seen in real-world clinical practice, which overall supports the findings from RCTs [11-16].

\section{CONCLUSIONS}

Overall, the systematic literature review of real-world observational studies reaffirms the findings from clinical trials that liraglutide monotherapy or combination therapy with other OADs translates into therapeutic benefits for patients with T2DM in routine clinical practice.

\section{ACKNOWLEDGMENTS}

The authors would like to thank Sophie Boukouvalas (Pharmerit International) for her assistance with the NICE systematic literature review in the capacity of the second reviewer. The study sponsor, Novo Nordisk A/S (Søborg, Denmark), funded all costs associated with the development and publishing of the present manuscript. The article processing charges for this publication were funded by Novo Nordisk A/S. All named authors meet the International Committee of Medical Journal Editors (ICMJE) criteria for authorship for this manuscript, take responsibility for the integrity of the work as a whole, and have given final approval to the version to be published.

Disclosures. Amrita Ostawal is an employee of Pharmerit GmbH. Emina Mocevic is an employee of Novo Nordisk A/S. Nana Kragh is an employee and shareholder of Novo Nordisk $\mathrm{A} / \mathrm{S}$. Weiwei $\mathrm{Xu}$ is an employee of Pharmerit International.

Compliance with Ethics Guidelines. This article is based on previously conducted studies and does not involve any new studies of human or animal subjects performed by any of the authors.

Open Access. This article is distributed under the terms of the Creative Commons Attribution-NonCommercial 4.0 International License (http://creativecommons.org/licenses/ by-nc/4.0/), which permits any noncommercial use, distribution, and reproduction in any medium, provided you give appropriate credit to the original author(s) and the source, provide a link to the Creative Commons license, and indicate if changes were made.

\section{REFERENCES}

1. Cade WT. Diabetes-related microvascular and macrovascular diseases in the physical therapy setting. Phys Ther. 2008;88(11):1322-35. 
2. American Diabetes Association. Standards of medical care in diabetes-2014. Diabetes Care. 2014;37(Suppl 1):S14-80.

3. International Diabetes Federation. Treatment algorithm for people with type 2 diabetes. Available from https://www.idf.org/treatmentalgorithm-people-type-2-diabetes. Accessed Feb 3, 2016.

4. American Diabetes Association. Diabetes Management Guidelines. 2015. Available from: http://www.ndei.org/ADA-diabetes-managementguidelines-pharmacologic-therapy-for-type-2-dia betes.aspx. Accessed Feb 3, 2016.

5. AACE/ACE Comprehensive Diabetes Management Algorithm. 2015. Available from: https://www.aace. com/files/aace_algorithm.pdf. Accessed Feb 3, 2016.

6. National Institute for Health and Care Excellence. Algorithm for blood glucose lowering therapy in adults with type 2 diabetes. Available from: http:// www.nice.org.uk/guidance/ng28/resources/algorithmfor-blood-glucose-lowering-therapy-in-adults-withtype-2-diabetes-2185604173. Accessed Feb 3, 2016.

7. Inzucchi SE, Bergenstal RM, Buse JB, Diamant M, Ferrannini E, Nauck $M$, et al. Management of hyperglycemia in type 2 diabetes, 2015: a patient-centered approach: update to a position statement of the American Diabetes Association and the European Association for the Study of Diabetes. Diabetes Care. 2015;38(1):140-9.

8. Nauck MA, Kleine N, Orskov C, Holst JJ, Willms B, Creutzfeldt W. Normalization of fasting hyperglycaemia by exogenous glucagon-like peptide 1 (7-36 amide) in type 2 (non-insulin-dependent) diabetic patients. Diabetologia. 1993;36(8):741-4.

9. Doyle ME, Egan JM. Mechanisms of Action of GLP-1 in the Pancreas. Pharmacol Ther. 2007;113(3):546-93.

10. Novo Nordisk. Novo Nordisk Annual Report 2015. Available from: http://www.novonordisk.com/ content/dam/Denmark/HQ/Commons/documents/ Novo-Nordisk-Annual-Report-2015.PDF. Accessed Feb 3, 2016.

11. Marre M, Shaw J, Brandle M, Bebakar WM, Kamaruddin NA, Strand J, et al. Liraglutide, a once-daily human GLP-1 analogue, added to a sulphonylurea over 26 weeks produces greater improvements in glycaemic and weight control compared with adding rosiglitazone or placebo in subjects with Type 2 diabetes (LEAD-1 SU). Diabet Med. 2009;26(3):268-78.
12. Nauck M, Frid A, Hermansen K, Shah NS, Tankova $\mathrm{T}$, Mitha IH, et al. Efficacy and safety comparison of liraglutide, glimepiride, and placebo, all in combination with metformin, in type 2 diabetes: the LEAD (liraglutide effect and action in diabetes)-2 study. Diabetes Care. 2009;32(1):84-90.

13. Garber A, Henry R, Ratner R, Garcia-Hernandez PA, Rodriguez-Pattzi H, Olvera-Alvarez $\mathrm{I}$, et al. Liraglutide versus glimepiride monotherapy for type 2 diabetes (LEAD-3 Mono): a randomised, 52-week, phase III, double-blind, parallel-treatment trial. Lancet. 2009;373(9662):473-81.

14. Zinman B, Gerich J, Buse JB, Lewin A, Schwartz S, Raskin $P$, et al. Efficacy and safety of the human glucagon-like peptide-1 analog liraglutide in combination with metformin and thiazolidinedione in patients with type 2 diabetes (LEAD- 4 Met + TZD). Diabetes Care. 2009;32(7):1224-30.

15. Russell-Jones D, Vaag A, Schmitz O, Sethi BK, Lalic $\mathrm{N}$, Antic $\mathrm{S}$, et al. Liraglutide vs insulin glargine and placebo in combination with metformin and sulfonylurea therapy in type 2 diabetes mellitus (LEAD-5 met + SU): a randomised controlled trial. Diabetologia. 2009;52(10):2046-55.

16. Buse JB, Rosenstock J, Sesti G, Schmidt WE, Montanya E, Brett JH, et al. Liraglutide once a day versus exenatide twice a day for type 2 diabetes: a 26-week randomised, parallel-group, multinational, open-label trial (LEAD-6). Lancet. 2009;374(9683):39-47.

17. Nauck M, Rizzo M, Pirags V. Once-daily liraglutide vs. lixisenatide as add-on to metformin in type 2 diabetes: a 26-week randomised controlled clinical trial. Abstract number 75. In: Presented at The 51st Annual Meeting of the European Association of Diabetes (EASD). 2015.

18. Pratley RE, Nauck MA, Barnett AH, Feinglos MN, Ovalle F, Harman-Boehm I, et al. Once-weekly albiglutide versus once-daily liraglutide in patients with type 2 diabetes inadequately controlled on oral drugs (HARMONY 7): a randomised, open-label, multicentre, non-inferiority phase 3 study. Lancet Diabetes Endocrinol. 2014;2(4):289-97.

19. Dungan KM, Povedano ST, Forst T, González JGG, Atisso C, Sealls W, et al. Once-weekly dulaglutide versus once-daily liraglutide in metformin-treated patients with type 2 diabetes (AWARD-6): a randomised, open-label, phase 3 , non-inferiority trial. Lancet. 2014;384(9951):1349-57.

20. Buse JB, Nauck M, Forst T, Sheu WHH, Shenouda SK, Heilmann CR, et al. Exenatide once weekly versus liraglutide once daily in patients with type 2 
diabetes (DURATION-6): a randomised, open-label study. Lancet. 2013;381(9861):117-24.

21. Pratley RE, Nauck M, Bailey T, Montanya E, Cuddihy R, Filetti $S$, et al. Liraglutide versus sitagliptin for patients with type 2 diabetes who did not have adequate glycaemic control with metformin: a 26-week, randomised, parallel-group, open-label trial. Lancet. 2010;375(9724):1447-56.

22. Pratley R, Nauck M, Bailey T, Montanya E, Cuddihy $\mathrm{R}$, Filetti $\mathrm{S}$, et al. One year of liraglutide treatment offers sustained and more effective glycaemic control and weight reduction compared with sitagliptin, both in combination with metformin, in patients with type 2 diabetes: a randomised, parallel-group, open-label trial. Int J Clin Pract. 2011;65(4):397-407.

23. Pratley RE, Nauck MA, Bailey T, Montanya E, Filetti S, Garber AJ, et al. Efficacy and safety of switching from the DPP-4 inhibitor sitagliptin to the human GLP-1 analog liraglutide after 52 weeks in metformin-treated patients with type 2 diabetes: a randomized, open-label trial. Diabetes Care. 2012;35(10):1986-93.

24. Kaku K, Kiyosue A, Ono Y, Shiraiwa T, Kaneko S, Nishijima $\mathrm{K}$, et al. Liraglutide is effective and well tolerated in combination with an oral antidiabetic drug in Japanese patients with type 2 diabetes: a randomized, 52-week, open-label, parallel-group trial. J Diabetes Investig. 2016;7(1):76-84.

25. Seino Y, Kaneko S, Fukuda S, Osonoi T, Shiraiwa T, Nishijima $K$, et al. Combination therapy with liraglutide and insulin in Japanese subjects with type 2 diabetes: a 36-week, randomized, double-blind, parallel-group trial. J Diabetes Investig. 2016.

26. National Institute for Health and Clinical Excellence. Guide to the methods of technology appraisal 2013. Available at: https://www.nice.org.uk/article/pmg9/ chapter/foreword. Accessed Feb 3, 2016.

27. Centre for Reviews and Dissemination. Systematic reviews: CRD's guidance for undertaking reviews in healthcare. Centre for Reviews and Dissemination: University of York; 2009.

28. Buysman EK, Liu F, Hammer M, Langer J. Impact of medication adherence and persistence on clinical and economic outcomes in patients with type 2 diabetes treated with liraglutide: a retrospective cohort study. Adv Ther. 2015;32(4):341-55.

29. Buysschaert M, D'Hooge D, Preumont V, Roots Study Group. ROOTS: a multicenter study in Belgium to evaluate the effectiveness and safety of liraglutide (Victoza) in type 2 diabetic patients. Diabetes Metab Syndr. 2015;9(3):139-42.
30. Chiefari E, Capula C, Vero A, Oliverio R, Puccio L, Liguori R, et al. Add-on treatment with liraglutide improves glycemic control in patients with type 2 diabetes on metformin therapy. Diabetes Technol Ther. 2015;17(7):468-74.

31. Cotugno M, Nosso G, Saldalamacchia G, Vitagliano G, Griffo E, Lupoli R, et al. Clinical efficacy of bariatric surgery versus liraglutide in patients with type 2 diabetes and severe obesity: a 12-month retrospective evaluation. Acta Diabetol. 2015;52(2):331-6.

32. Evans M, McEwan P, O'Shea R, George L. A retrospective, case-note survey of type 2 diabetes patients prescribed incretin-based therapies in clinical practice. Diabetes Ther. 2013;4(1):27-40.

33. Evans M, McEwan P, O'Shea R, George L. Efficacité en pratique clinique courante des incrétino-mimétiques dans le traitement du diabète de type 2: résultats d'une enquête nationale rétrospective au Royaume-Uni. Méd Mal Métab. 2014;8(2):177-83.

34. Fadini GP, Simioni N, Frison V, Dal Pos M, Bettio M, Rocchini $\mathrm{P}$, et al. Independent glucose and weight-reducing effects of Liraglutide in a real-world population of type 2 diabetic outpatients. Acta Diabetol. 2013;50(6):943-9.

35. Funch D, Gydesen H, Tornoe K, Major-Pedersen A, Chan KA. A prospective, claims-based assessment of the risk of pancreatitis and pancreatic cancer with liraglutide compared to other antidiabetic drugs. Diabetes Obes Metab. 2014;16(3):273-5.

36. Gautier JF, Martinez L, Penfornis A, Eschwege E, Charpentier G, Huret B, et al. Effectiveness and persistence with liraglutide among patients with type 2 diabetes in routine clinical practice-EVIDENCE: a prospective, 2-year follow-up, observational, post-marketing study. Adv Ther. 2015;32(9):838-53.

37. Ghuman NK, Saadah LM, Al Najjar MS, Shaheen DY, Am SI, Al Ali MM. Effectiveness of liraglutide in type II diabetes mellitus management: experience in emirati patients. Clin Med Insights Endocrinol Diabetes. 2015;8:67-72.

38. Inoue K, Maeda N, Fujishima Y, Fukuda S, Nagao H, Yamaoka M, et al. Long-term impact of liraglutide, a glucagon-like peptide-1 (GLP-1) analogue, on body weight and glycemic control in Japanese type 2 diabetes: an observational study. Diabetol Metab Syndr. 2014;6(1):95.

39. Lapolla A, Frison V, Bettio M, Dal Pos M, Rocchini $P$, Panebianco G, et al. Correlation between baseline characteristics and clinical outcomes in a large population of diabetes patients treated with 
liraglutide in a real-world setting in Italy. Clin Ther. 2015;37(3):574-84.

40. Ohki $\mathrm{T}$, Isogawa $\mathrm{A}$, Iwamoto $\mathrm{M}$, Ohsugi $\mathrm{M}$, Yoshida $\mathrm{H}$, Toda $\mathrm{N}$, et al. The effectiveness of liraglutide in nonalcoholic fatty liver disease patients with type 2 diabetes mellitus compared to sitagliptin and pioglitazone. ScientificWorldJournal. 2012;2012:496453.

41. Perušičová J, Skupina, Pithová a pracovní P. Vliv inkretinového mimetika liraglutidu (Victoza) na hmotnost a hladiny glykovaného hemoglobinu u nemocných s diabetes mellitus 2. typu $\mathrm{v}$ diabetologických ordinacích ČR-studie BIVI. Interní medicína pro praxi. 2013;15(5):170-5.

42. Ponzani P. Long-term effectiveness and safety of liraglutide in clinical practice. Miner Endocrinol. 2013;38(1):103-12.

43. Rigato M, Avogaro A, Fadini GP. Effects of dose escalating liraglutide from 1.2 to $1.8 \mathrm{mg}$ in clinical practice: a case-control study. J Endocrinol Invest. 2015;38(12):1357-63.

44. Russo GT, Labate AM, Giandalia A, Romeo EL, Villari P, Alibrandi A, et al. Twelve-month treatment with Liraglutide ameliorates Visceral Adiposity Index and common cardiovascular risk factors in type 2 diabetes outpatients. J Endocrinol Invest. 2015;38(1):81-9.

45. Thomsen RW, Baggesen LM, Sogaard M, Pedersen L, Norrelund H, Buhl ES, et al. Early glycaemic control in metformin users receiving their first add-on therapy: a population-based study of 4,734 people with type 2 diabetes. Diabetologia. 2015;58(10):2247-53.

46. Vitagliano G, Nosso G, Cotugno M, Saldalamacchia G, Lupoli R, Griffo E, et al. One-year efficacy of liraglutide or bariatric surgery in obese type 2 diabetic patients: a retrospective study. G Ital Diabetol Metabol. 2014;34(2):58-63.

47. Zavattaro M, Caputo M, Sama MT, Mele C, Chasseur L, Marzullo P, et al. One-year treatment with liraglutide improved renal function in patients with type 2 diabetes: a pilot prospective study. Endocrine. 2015;50(3):620-6.

48. Bashier AM, Hussain AA, Abdelgadir EI, Eltinay AT, Thadani $\mathrm{P}$, Abdalla ME, et al. Liraglutide effect in reducing HbA1c and weight in Arab population with type2 diabetes, a prospective observational trial. J Diabetes Metab Disord. 2015;14:48.

49. Chitnis AS, Ganz ML, Benjamin N, Langer J, Hammer M. Clinical effectiveness of liraglutide across body mass index in patients with type 2 diabetes in the United States: a retrospective cohort study. Adv Ther. 2014;31(9):986-99.

50. DeKoven M, Lee WC, Bouchard J, Massoudi M, Langer J. Real-world cost-effectiveness: lower cost of treating patients to glycemic goal with liraglutide versus exenatide. Adv Ther. 2014;31(2):202-16.

51. Heymann A, Maor Y, Goldstein I, Todorova L, Schertz-Sternberg P, Karasik A. Efficacy of liraglutide in a real-life cohort. Diabetes Ther. 2014;5(1):193-206.

52. Kesavadev J, Shankar A, Gopalakrishnan G, Jothydev S. Efficacy and safety of liraglutide therapy in 195 Indian patients with type 2 diabetes in real world setting. Diabetes Metab Syndr. 2015;9(1):30-3.

53. Kesavadev J, Shankar A, Krishnan G, Jothydev S. Liraglutide therapy beyond glycemic control: an observational study in Indian patients with type 2 diabetes in real world setting. Int J Gen Med. 2012;5:317-22.

54. Kondo Y, Satoh S, Nagakura J, Kimura M, Nezu U, Terauchi Y. Defining criteria for the introduction of liraglutide using the glucagon stimulation test in patients with type 2 diabetes. J Diabetes Investig. 2013;4(6):571-5.

55. Kondo Y, Satoh S, Osada UN, Terauchi Y. Early liraglutide treatment improves beta-cell function in patients with type 2 diabetes: a retrospective cohort study. Endocr J. 2015;62(11):971-80.

56. Li Q, Chitnis A, Hammer M, Langer J. Real-world clinical and economic outcomes of liraglutide versus sitagliptin in patients with type 2 diabetes mellitus in the United States. Diabetes Ther. 2014;5(2):579-90.

57. Mezquita-Raya P, Reyes-Garcia R, Moreno-Perez O, Escalada-San Martin J, Angel Rubio Herrera M, Lopez de la Torre Casares M. Clinical effects of liraglutide in a real-world setting in Spain: eDiabetes-Monitor SEEN Diabetes Mellitus Working Group Study. Diabetes Ther. 2015;6(2):173-85.

58. Nyeland ME, Ploug UJ, Richards A, Garcia Alvarez L, Demuth D, Muthutantri A, et al. Evaluation of the effectiveness of liraglutide and sitagliptin in type 2 diabetes: a retrospective study in UK primary care. Int J Clin Pract. 2015;69(3):281-91.

59. Rizzo MCM, Patti AM, Di Bartolo V, Rizvi AA, Montalto G, Abate N. Liraglutide decreases carotid intima-media thickness in patients with type 2 diabetes: 8-month prospective pilot study. Cardiovasc Diabetol. 2014;13:49. 
60. Thong KY, McDonald TJ, Hattersley AT, Blann AD, Ramtoola S, Duncan C, et al. The association between postprandial urinary C-peptide creatinine ratio and the treatment response to liraglutide: a multi-centre observational study. Diabet Med. 2014;31(4):403-11.

61. Toyoda M, Yokoyama H, Abe K, Nakamura S, Suzuki D. Predictors of response to liraglutide in Japanese type 2 diabetes. Diabetes Res Clin Pract. 2014;106(3):451-7.

62. Varanasi A, Patel P, Makdissi A, Dhindsa S, Chaudhuri A, Dandona P. Clinical use of liraglutide in type 2 diabetes and its effects on cardiovascular risk factors. Endocr Pract. 2012;18(2):140-5.

63. Ahern T, Tobin AM, Corrigan M, Hogan A, Sweeney C, Kirby B, et al. Glucagon-like peptide-1 analogue therapy for psoriasis patients with obesity and type 2 diabetes: a prospective cohort study. J Eur Acad Dermatol Venereol. 2013;27(11):1440-3.

64. Diaz-Soto G, de Luis DA, Conde-Vicente R, Izaola-Jauregui $\mathrm{O}$, Ramos $\mathrm{C}$, Romero E. Beneficial effects of liraglutide on adipocytokines, insulin sensitivity parameters and cardiovascular risk biomarkers in patients with Type 2 diabetes: a prospective study. Diabetes Res Clin Pract. 2014;104(1):92-6.

65. Gomez-Peralta F, Abreu C, Castro JC, Alcarria E, Cruz-Bravo M, Garcia-Llorente MJ, et al. An association between liraglutide treatment and reduction in excessive daytime sleepiness in obese subjects with type 2 diabetes. BMC Endocr Disord. 2015;15(1):78.

66. Jinnouchi H, Sugiyama S, Yoshida A, Hieshima K, Kurinami N, Suzuki $\mathrm{T}$, et al. Liraglutide, a glucagon-like peptide-1 analog, increased insulin sensitivity assessed by hyperinsulinemic-euglycemic clamp examination in patients with uncontrolled type 2 diabetes mellitus. J Diabetes Res. 2015;2015:706416.

67. Kaur P, Mishra SK, Mithal A, Saxena M, Makkar A, Sharma P. Clinical experience with Liraglutide in 196 patients with type 2 diabetes from a tertiary care center in India. Indian J Endocrinol Metab. 2014;18(1):77-82.

68. Mori Y, Taniguchi Y, Sezaki K, Yokoyama J, Utsunomiya K. Liraglutide narrows the range of circadian glycemic variations in Japanese type 2 diabetes patients and nearly flattens these variations in drug-naive type 2 diabetes patients: a continuous glucose monitoring-based study. Diabetes Technol Ther. 2011;13(11):1139-44.
69. Mulligan CM, Harper R, Harding J, Mcllwaine W, Petruckevitch A, McLaughlin DM. A retrospective audit of type 2 diabetes patients prescribed liraglutide in real-life clinical practice. Diabetes Ther. 2013;4(1):147-51.

70. Usui R, Yabe D, Kuwata H, Fujiwara S, Watanabe K, Hyo $\mathrm{T}$, et al. Retrospective analysis of safety and efficacy of insulin-to-liraglutide switch in Japanese type 2 diabetes: a caution against inappropriate use in patients with reduced beta-cell function. J Diabetes Investig. 2013;4(6):585-94.

71. Gomez-Peralta F, Castro JC, Alcarria E, Cruz-Bravo M, Garcia-Llorente MJ, Albornos C, et al. Almodovar influence of liraglutide treatment in obstructive sleep apnea (OSA) in patients with obesity and diabetes mellitus type $2 ; 2013$.

72. Jepsen P, Johnsen SP, Gillman MW, Sørensen HT. Interpretation of observational studies. Heart. 2004;90(8):956-60.

73. DeKoven M, Lee W, Bouchard J, Edwy M, Langer J. Improved real-world glycemic outcomes with liraglutide versus other incretin-based therapies in type 2 diabetes. In: Presented at The American Diabetes Association (ADA) 73rd scientific sessions, June 21-25, Chicago, Illinois 2013.

74. National Institute for Health and Clinical Excellence (NICE). Type 2 diabetes in adults: management NICE guidelines [NG28] Published date: December 2015. Available from: http://www.nice.org. uk/guidance/ng28/chapter/1-Recommendations\#hba 1c-measurement-and-targets. Accessed Feb 3, 2016.

75. Rodbard HW, Jellinger PS, Davidson JA, Einhorn D, Garber AJ, Grunberger G, et al. Statement by an American Association of Clinical Endocrinologists/ American College of Endocrinology consensus panel on type 2 diabetes mellitus: an algorithm for glycemic control. Endocr Pract. 2009;15(6):540-59.

76. American Diabetes Association. Standards of medical care in diabetes - 2013. Diabet Care. 2013;36(1):S11-66.

77. Poirier P, Giles TD, Bray GA, Hong Y, Stern JS, Pi-Sunyer FX, et al. Obesity and cardiovascular disease: pathophysiology, evaluation, and effect of weight loss. Arterioscler Thromb Vasc Biol. 2006;26(5):968-76.

78. Gautier JF, Penfornis A, Charpentier G, Bouzidi A, Madani S, Martinez L, et al. The proportion of patients successfully treated with liraglutideresults from a post-hoc analysis of the EVIDENCE study. In: Presented at the 75th scientific sessions American Diabetes Association (ADA) 2015, June 5-9, 2015, Boston, MA, USA; 2015. 
79. Matsson P, Lind M, Johansson G, Svenningsson I, Jörgensen L, Ploug $\mathrm{U}$, et al. A retrospective assessment of clinical effectiveness in type 2 diabetes patients treated with liraglutide or sitagliptin from primary care centers in Sweden. In: Presented at The SFD 7-8 May 2015; 2015.

80. Heymann A, Maor Y, Goldstein I, Todorava L, Schertz-Sternberg P, Karasik A. Real life evidence of liraglutide effects supports efficacy shown in RCTs. In: Presented at The World Diabetes Congress, Melbourne, 2-6 December 2013; 2013.

81. Karasik A, Heymann A, Sternberg P, Leshno M, Todorova L, Goldshtein I, et al. Real life effects of liraglutide supports those shown in RCTs. In: Presented at The ISPOR 16th Annual European Congress, Dublin; 2-6th November 2013.

82. Fatima J, Pearce S. The use of GLP-1 agonist liraglutide: adhereing to guidelines? Diabetic Medicine. 2014;31(Suppl 1):28-123. Abstract P154. Abstracts of the Diabetes UK Professional Conference, 5-7 March 2014.

83. Degn KB, Juhl CB, Sturis J, Jakobsen G, Brock B, Chandramouli $\mathrm{V}$, et al. One week's treatment with the long-acting glucagon-like peptide 1 derivative liraglutide (NN2211) markedly improves 24-h glycemia and alpha- and beta-cell function and reduces endogenous glucose release in patients with type 2 diabetes. Diabetes. 2004;53(5):1187-94.

84. Mari A, Sallas WM, He YL, Watson C, Ligueros-Saylan M, Dunning BE, et al. Vildagliptin, a dipeptidyl peptidase-IV inhibitor, improves model-assessed beta-cell function in patients with type 2 diabetes. J Clin Endocrinol Metab. 2005;90(8):4888-94.

85. Buse JB, Sesti G, Schmidt WE, Montanya E, Chang $\mathrm{CT}, \mathrm{Xu} \mathrm{Y}$, et al. Switching to once-daily liraglutide from twice-daily exenatide further improves glycemic control in patients with type 2 diabetes using oral agents. Diabetes Care. 2010;33(6):1300-3.

86. Thong KY, Sen Gupta P, Ryder REJ, ABCD nationwide exenatide and liraglutide audit contributors. The efficacy of exenatide and liraglutide among South Asians in the Association of British Clinical Diabetologists nationwide audits. In: Abstract book, 22nd World Diabetes Congress, IDF, Melbourne, Australia; 2-6 December 2013.

87. Victoza. Summary of Product Characteristics. Available from: http://www.ema.europa.eu/docs/en GB/document_library/EPAR_-_Product_Information/ human/001026/WC500050017.pdf. Accessed Feb 3, 2016.

88. Zinman B, Buse J, Falahati S, Moses A. Attaining a clinically relevant endpoint of $\mathrm{HbA} 1 \mathrm{c}<7.0 \%$, no weight gain and no hypoglycaemia with liraglutide as compared to other therapies in type 2 diabetes mellitus: a meta-analysis of the LEAD studies. Diabetologia. 2009;52(Suppl 1):S291.

89. Davies MJ, Kela R, Khunti K. Liraglutide-overview of the preclinical and clinical data and its role in the treatment of type 2 diabetes. Diabetes Obes Metab. 2011;13(3):207-20. 